\title{
Investigation of Real Power Flow Control of Al Based MC-UPFC in FACTS Controllers
}

\author{
Boopalan Chandran ${ }^{1}$, Saravanan Vasudevan ${ }^{2}$ and Raghavendiran T. A. ${ }^{3}$ \\ 1. Anna University, Chennai 600025, India \\ 2. Arunai Engineering College, Tiruvannamalai 606603, India \\ 3. Sri venakateswara Engineering College for Women, Tirupathi 517507, India
}

\begin{abstract}
The power consumption is rapidly increased due to ASD (Adjustable Speed Drives) and automation in industries and large consumption of electricity in domestic regions increased the concern of the power quality. The quality of the power received in the distribution system is altered because of the losses in the transmission system. The losses in the transmission system are mitigated using the FACTS (Flexible AC Transmission System) controller, among these controllers UPFC (Unified Power Flow Controller) plays a vital role in controlling the shunt and series reactive powers in the bus of the power system. The conventional topology of the UPFC consists of AC-DC converter and energy stored in the DC link and DC-AC converter injected a voltage in series to the bus which is to be controlled. Whereas a new topology based on matrix converter can replace the dual converters and perform the required task. The construction of 2-bus, 7-bus and IEEE-14-bus power system is designed and modeled. MC-UPFC (Matrix Converter Based Unified Power Flow Controller) is designed and constructed. The MC-UPFC is the rich topology in the FACTS which is capable of controlling both the transmission parameters simultaneously with the switching technique of direct power control by the smooth sliding control which gives less ripple in the injecting control parameters such as control voltage $\left(V_{c}\right)$ and voltage angle $(\alpha)$. By implementing MC-UPFC the real and reactive power can be controlled simultaneously and independently. The control techniques were designed based on the PID (Proportional Integral Derivative) with sliding surface power control, FLC (Fuzzy Logic Controller) and ANN (Artificial Neural Network) and the performances of $V_{c}$ and $\alpha$ of the controllers are investigated. Hence the sliding surface and relevant control switching state of the MC can be controlled by the FLC which gives the robust and autonomous decision made in the selection of the appropriate switching state for the effective real power control in the power system. The work has been carried out in the MATLAB Simulink simulator which gives the finest controlling features and simple design procedures and monitoring of the output.
\end{abstract}

Key words: Matrix converter, unified power flow controller, fuzzy logic controller.

\section{Introduction}

The advancement in the field of electrical and electronics engineering leads to an increase in the utilization of electric energy in the lifestyle of mankind. Due to the rapid rise of power demand among consumers, engineers need to increase the production, optimize the power generation and reduce the losses in the transmission system. To reduce the losses in the power transmission system and to maintain the quality of the power, various control schemes are developed under the FACTS (Flexible AC Transmission System) [1-9]. UPFC (Unified Power Flow Controller) is one of

Corresponding author: Boopalan Chandran, B.E., M. Tech., research field: electrical engineering. the FACTS devices, which has gained more popularity in recent years in power system control. UPFC can perform the action of shunt voltage conversion and series current injection with the Direct Current (DC) storage between the converters. The major functions of the UPFC are to control the real and reactive power flow. Such unique characteristics of UPFCs made them popular in applications. With the help of UPFC, the steady-state control and the dynamic control of the transmission network can be achieved [10-16]. Prior to utilization, the generated power supply should overcome two losses, namely, the generation loss and transmission loss, where the loss occurring on the transmission sector provides a large contribution. The losses in the transmission sector occur in different ways 
such as real and reactive power loss, power system parameters, and quality losses. In our proposed system the pattern of switching scheme will be based on the need of the system. The gate controller will receive the decision taken by the artificial intelligent controlling system. The space vector based technique is used in power flow control. The proposed system of artificial intelligence implemented MC-UPFC consists of 9 controlling switches arranged in $3 \times 3$ matrix pattern which has connected to the transmission system with the shunt transformer at the input side and series transformer in the output side. The proposed FLC (Fuzzy Logic Controller) based MC-UPFC controls the power flow in the bus with the power injection with power angle.

The overall interest of the various facts devices over a period of two decades and the chart show that the gradual and consistent increase in the research interest of UPFC will most likely yield solutions to most common power transmission system issues due to its wider controlling region shown in Fig. 1.

UPFC is capable of controlling active power and the reactive power separately without depending on each other.

The control can be achieved for:

(a) generator side and for the load side comfortably;

(b) converter switching controlled transmission line series capacitor or DC link; (c) the regulation of phase angle using thyristor switching techniques for different conditions achieved by using GTO thyristor as inverter with source as voltage [17-20].

UPFC benefits the power system by increasing the power transferring ability between the power systems: the shunt converter controls the real power and the series converter controls the reactive power also identifies the limit in the injecting current. STATCOM (Static Shunt Compensator) is used as shunt converter and SSSC (Static Synchronous Series Compensator) is used as series inverter. The size of each component in UPFC, power rating in KVA of the series and shunt transformers used in injection of current and absorption of voltage in the transmission line are estimated. The major constraints in the design and implementation of UPFC are:

- injected voltage;

- inverter current;

- converter current;

- range of line voltage to UPFC;

- power converting capability of UPFC.

In addition the limiting factors such as shunt UPFC controls instantaneously the basic parameters with the help of modified controlling strategy using the prediction of pre-control signal at the DC-link proposed the following controlling techniques:

- Watt-VAR Decoupled technique;

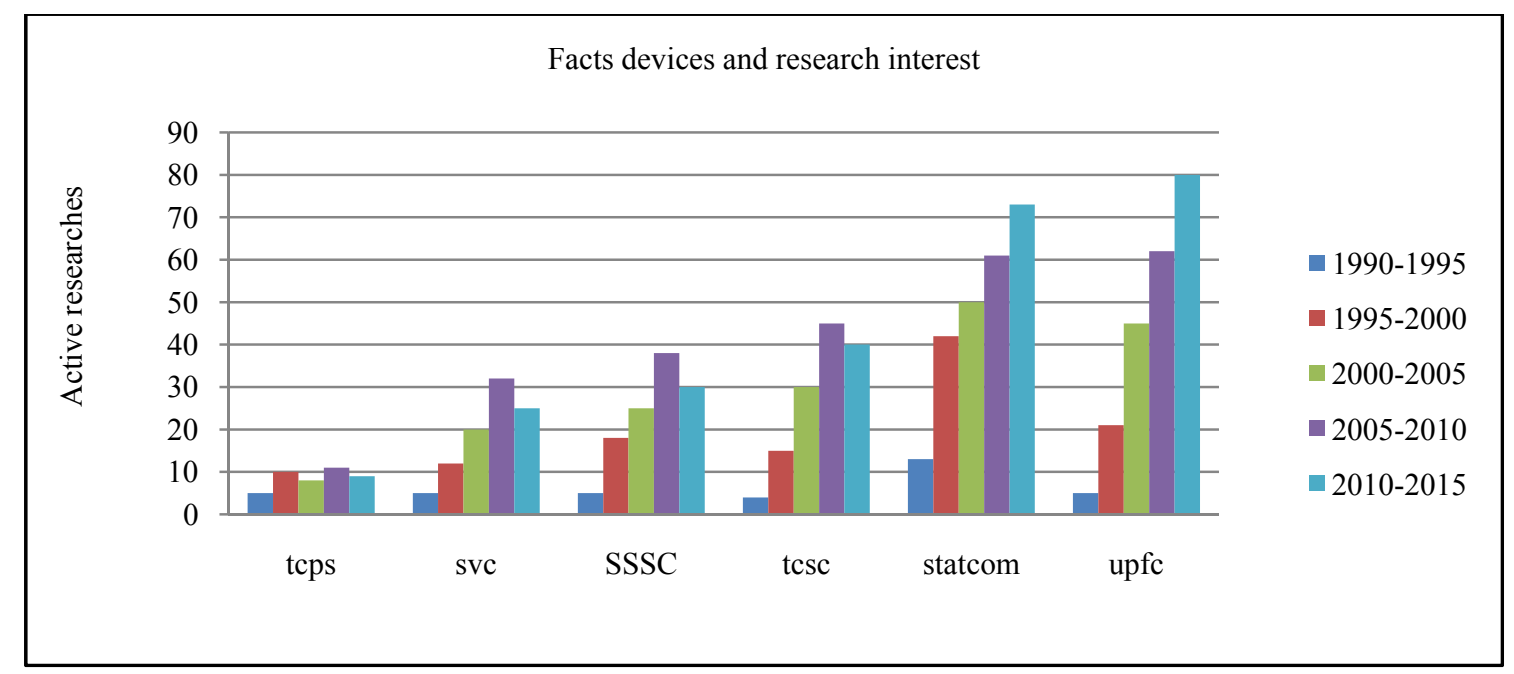

Fig. 1 Role of UPFC among FACTS devices. 
- Modified Decoupled technique;

- Control of bus voltage at DC side.

In real time two slack bus is with $\delta=20^{\circ}, 6$-pulse switching scheme with 3-level. The EPRI and WAPA (Western Area Power Administration) are constructed in Westinghouse. Synchronous Compensator is installed and implemented in full scale with following studies:

- stability of voltage;

- stability of small signals;

- transient state;

- stability in high frequency;

- stability in low frequency.

Such studies revealed that UPFC is giving better performance.

Three-phase power electronic circuit with 9 switches in three limbs $(3 \times 3)$, each input voltage can be injected to any phase of the output side, developed a UPFC with MC controlled by Advanced DPC (Direct Power Control). To increase the smooth control, the authors have implemented a sliding mode strategy. The designed control technique was compared with the venturini method to prove the improved performance. Also linear control algorithm is developed for MC-UPFC. To validate the proposed system, software simulation is modeled and compared with the practical experiment with the ratings of $1,500 \mathrm{VA}$. Their model resulted in quick response, good steady state performance and independent control among real and reactive power [13-15].

The UPFC is working with the reference input signal and based on the reference the control will switch to reduce the error between the real-time values and the reference values. To achieve the reference power parameters, controllers like proportional-integral controllers and proportional-integral-derivative controllers are applied.

PI controllers will give the control signal according to the input given to it, along with the appropriate proportionate and integrated value of the error signal between the reference signal and the feedback signal.
The weight of each linguistic input parameter was calculated for every membership function and the rule was framed based on "if-then" condition. The processed data will be defuzzified and fed as the output of the FLC. The output of the defuzzifying block is given to the switching pulse block to provide the gate signal to the switching devices. FLC based algorithms are widely applied for the power system control issues such as SVC, TCSC, IPFC, and UPFC. Most commonly the triangular membership inference functions were preferred. FLC is commonly used because of its accuracy and high efficiency in error detection and responses.

\section{Modeling of MC-UPFC in Power System}

To analyze the performance of any electric power system, it has to be simplified into basic parameters and redrawn into simple electric circuit. Our scope of investigation needs to reduce the 2, 9 and 14-bus power system's total number of power source (generators) into a single source and all buses available at the power system are reduced into single load bus and the transmission line parameters are reduced into a simple passive RL circuit. This process of modeling helps us to directly monitor and investigate the power flow parameters in the power improvement aspect [15-20].

\section{$2.12,9 \& 14-B u s$ System}

The power system is determined based on the size of the bus count. Based on the numbers of buses the number of nodes of measurement is calculated. In a two-bus system the scope of measurement of the line parameters is taken at bus-1 (sending end) and bus- 2 (receiving end). These two buses are available at both the end of transmission line. The schematic diagram of the simple two-bus system is shown in Fig. 2 while the equivalent circuit of the matrix converter incorporated power system with the injection control voltage is shown in Fig. 3. In the two-bus system, we have a sending end generator and a power transformer after which a transmission system is connected and at the 


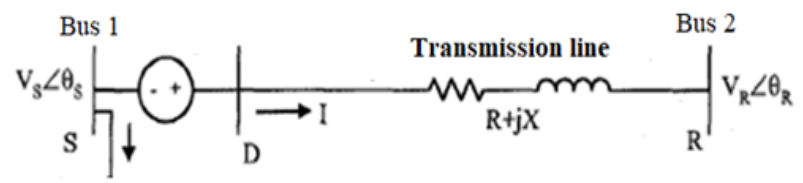

Fig. 2 2-bus power systems.

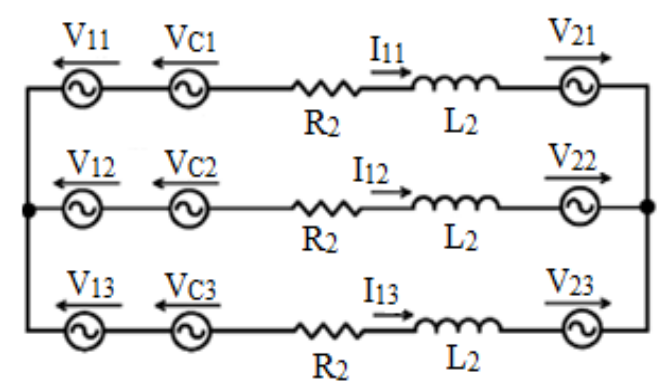

Fig. 3 Equivalent circuit MC-UPFC for 2-bus system.

end of the transmission system through power transformer receiving end load is connected.

In bus No. 1, the voltage available is mentioned as $V s<\theta_{n}$ and the voltage available at bus No. 2 is mentioned as $V s<\theta_{n}$ and the transmission line parameter is simplified into $R+j X$. As shown in Fig. 2, the simplified circuit diagram of the 2 bus system with the single voltage source and receiving end bus voltage $V_{1}$ controlled by the $V_{2}$ with its phasor diagram shows the difference between the sending and receiving end voltage angle. The phasor diagram shows that the series inverter voltage $V_{1}$ and Shunt side voltage $V_{s h}$ are the two controllable voltage sources. Both voltages are perpendicular where one is in-phase with the input volt called $V_{s h}$ and the other in out-phase called $V_{1}$ with the angle of $\alpha$. The contour in the real and reactive power axis shows the smooth control region with its voltage and voltage angle. Fig. 2 shows the control region at which the real and reactive power control can be achieved smoothly in the PQ axis.

The following factors are to be considered while understanding the control of the line parameters:

(1) shunt voltage input to MC-UPFC;

(2) series injected line current;

(3) the least line voltage input;

(4) the least output line voltage.

The shunt and series voltages are the two factors used to control the real and reactive power flow from the MC-UPFC [21-29].

$$
\begin{array}{r}
S_{1}=P_{1}+j Q_{1} \\
S_{1}=V_{1} *\left[\frac{V_{1}-V_{2}}{Z_{l}}\right]
\end{array}
$$

where $S_{1}$ is apparent power available in the bus one, $P_{1}$ and $Q_{1}$ are the real and reactive power with respect to bus- 1 and bus- 2 . The line current injecting limit can be obtained by the following relationship.

$$
I=\frac{V_{1}+V_{i}-V_{2}}{Z_{l}}
$$

If the line current falls due to load, the injecting current can be calculated based on the ratio between the bus voltage and the load impedance. Stated in the above relationship, for $n$-bus system the power and the voltage parameters can be calculated as follows:

Real power $P(t)=\sum_{n=1}^{\infty} V_{n} * I_{n} \cos \theta_{n}$

Reactive power $Q(t)=\sum_{n=1}^{\infty} V_{n} * I_{n} \sin \theta_{n}$

$$
I(t)=\sum_{n=1}^{\infty} \sqrt{2} V_{n} \sin (n \omega t)
$$

Average active power

$$
P(t)=\sum_{n=1}^{\infty} \sqrt{2} V_{n} \cos \left(n \omega t+\emptyset_{n}\right)
$$

where $V_{n}$ and $I_{n}$ are rms value of voltage and current of $n^{\text {th }}$ harmonics and $\emptyset_{n}$ is phase difference at $n^{\text {th }}$ harmonics of voltage and current. The power flow of $n$ number of bus power system can be calculated with the following equation with UPFC connected in $k^{\text {th }}$ bus.

$P_{k}=P_{U}+\sum_{n=1}^{\infty}\left|V_{k}\right|\left|V_{j}\right|\left|Y_{k j}\right| \cos \left(\delta_{k}-\delta_{j}-\theta_{k j}\right)$

$Q_{k}=Q_{U}+\sum_{n=1}^{\infty}\left|V_{k}\right|\left|V_{j}\right|\left|Y_{k j}\right| \sin \left(\delta_{k}-\delta_{j}-\theta_{k j}\right)$

The power equation given for the UPFC connected $n$-bus system is given by:

$$
P_{U}=G_{U}+\left|V_{j}\right|^{2}-\left|V_{k}\right|\left|E_{U}\right|\left|Y_{U}\right| \cos \left(\delta_{k}-\delta_{j}-\theta_{k j}\right)
$$

$$
Q_{U}=G_{U}+\left|V_{j}\right|^{2}-\left|V_{k}\right|\left|E_{U}\right|\left|Y_{U}\right| \sin \left(\delta_{k}-\delta_{j}-\theta_{k j}\right)
$$

where $P_{U}$ and $Q_{U}$ are the real and reactive power respectively injected to the system by UPFC.

The power system arrangemnt is made with the 9-bus system with three generator bus with IEEE 9-bus standard system. The power system consists of IEEE 
type-1 exciters, 6 transmission lines with three constant impdeance loads. The 9-bus system with the unit value of the line parameters and load parameters of each bus is taken as followed in Table A2 for the simulation study.

The third case was taken as IEEE 14-bus power system which comprises of 5 power generators with IEEE type-1 exciters, 3 synchronous compensators. There are 17 total transmission lines which fed 11 constant loads. The IEEE 14-bus system with the unit value of the line parameters and load parameters of each bus was taken as followed in Table A3 for the simulation study. The 14-bus power system with three generators fed to the system with the bus rating as follows. The simulation of the power system is achieved with the help of mathworks software named as MATLAB. The MATLAB software provides the platform to connect the power system components in a workbench format called as Simulink. In the simulink window with the help of Power GUI (Power Graphical User Interface) the simulation is executed and sampled the data.

2.1.1 Conventional Control Schemes for MC-UPFC

The control schemes available for the MC-UPFC are developed and performance analysis is studied for the conventional methods called PID (Proportional-Integral-Derivative) controller, SVM (Space Vector Modulation) based controller using DPC (Direct Power Controller) through sliding mode control techniques. To validate the study the 2-bus, 7-bus and 14-bus power system were developed in the simulation platform and the above mentioned control techniques were separately implemented and the performances were analyzed. The parameters taken for the analysis are the injected voltage and the angle at which injected to the bus. The voltage injected through series transformer connected in the bus, the current and power parameters.

The voltage controlled by the matrix converter and fed to the bus further was mentioned as $V_{c}$ with the change of phase angle $\delta$ from the bus voltage.
The power system taken here is symmetrical system where the load is three-phase balanced and the current flow in three phases is same at normal condition. The matrix converter is arranged and switched in a sequence so that each one phase of the input supply will be connected to the output side at a time. A three phase inductor capacitor based LC filter is corporate to ensure the smooth input currents to the MC-UPFC.

\subsection{MC-UPFC Modeling}

The real power and reactive power can be calculated in $\mathrm{dq}$ coordinated by using the following equation:

$$
\left[\begin{array}{l}
P_{o} \\
Q_{o}
\end{array}\right]=\left[\begin{array}{cc}
V_{d} & V_{q} \\
V_{q} & -V_{d}
\end{array}\right] *\left[\begin{array}{c}
I_{d} \\
I_{q}
\end{array}\right]
$$

where input volt and current in dq axis are mentioned as $V_{1 d}, V_{1 q}, I_{1 d}, I_{1 q}$ respectively. Similarly the matrix converter input volt and current will be mentioned as $V_{d}, V_{q}, I_{d}, I_{q}$. By assuming the voltages at the sending end as $V_{d}$ with the rotating frame of reference which is synchronized $V_{s q}$ as zero, the relationship between the input phase current and output phase current can be expressed as follows:

$$
\begin{aligned}
{\left[\begin{array}{lll}
V_{i 1} & V_{i 2} & V_{i 3}
\end{array}\right]^{T} } & =F\left[\begin{array}{lll}
V_{o 1} & V_{o 2} & V_{o 3}
\end{array}\right]^{T} \\
{\left[\begin{array}{lll}
I_{i 1} & I_{i 2} & I_{i 3}
\end{array}\right]^{T} } & =F^{T}\left[\begin{array}{lll}
I_{o 1} & I_{o 2} & I_{o 3}
\end{array}\right]^{T}
\end{aligned}
$$

To understand the function of matrix converter and its operation at various switching scheme the switches are given series of numbers from $\mathrm{c} 1$ to $\mathrm{c} 9$.

$$
C=\left[\begin{array}{lll}
c_{1} & c_{2} & c_{3} \\
c_{4} & c_{5} & c_{6} \\
c_{7} & c_{8} & c_{9}
\end{array}\right]
$$

If the switch state $C=1$ then the switch is turned $\mathrm{ON}$, it the switch state $C=0$ the switch will be turned OFF. By forming the possibilities of switching patterns from input to output side form 27 possibilities as represented in Table 1 . In the table $v_{o}$ and $\delta_{o}$ are the voltage injected and the angle at which voltage was injected respectively. To control the active and reactive power the above mentioned 27 possibilities of switching schemes are used. Based on the selection of switches, the instantaneous active power and reactive power will change. 
Table 1 Switching patterns.

\begin{tabular}{|c|c|c|c|c|c|c|}
\hline \multirow{2}{*}{ Switching state } & \multicolumn{3}{|c|}{ Output voltage each phase } & \multirow{2}{*}{-Switches in ON state } & \multirow{2}{*}{ Volt $v_{o}$} & \multirow{2}{*}{ Angle $\delta_{o}$} \\
\hline & $V_{A}$ & $V_{B}$ & $V_{C}$ & & & \\
\hline 1 & $\mathrm{~A}$ & $\mathrm{~B}$ & $\mathrm{~B}$ & $1,5,6$ & $+0.816 V_{A B}$ & 0 \\
\hline 2 & $\mathrm{~B}$ & $\mathrm{~A}$ & $\mathrm{~A}$ & $4,2,3$ & $-0.816 V_{A B}$ & 0 \\
\hline 3 & $\mathrm{~B}$ & $\mathrm{C}$ & $\mathrm{C}$ & $4,8,9$ & $+0.816 V_{B C}$ & 0 \\
\hline 4 & $\mathrm{C}$ & $\mathrm{B}$ & $\mathrm{B}$ & $7,5,6$ & $-0.816 V_{B C}$ & 0 \\
\hline 5 & $\mathrm{C}$ & A & A & $7,2,3$ & $+0.816 V_{A C}$ & 0 \\
\hline 6 & $\mathrm{~A}$ & $\mathrm{C}$ & $\mathrm{C}$ & $1,8,9$ & $-0.816 V_{A C}$ & 0 \\
\hline 7 & $\mathrm{~B}$ & A & $\mathrm{B}$ & $4,2,6$ & $+0.816 V_{A B}$ & 60 \\
\hline 8 & $\mathrm{~A}$ & $\mathrm{~B}$ & A & $1,5,3$ & $-0.816 V_{A B}$ & 60 \\
\hline 9 & $\mathrm{C}$ & $\mathrm{B}$ & $\mathrm{C}$ & $7,5,9$ & $+0.816 V_{B C}$ & 60 \\
\hline 10 & $\mathrm{~B}$ & $\mathrm{C}$ & $\mathrm{B}$ & $4,8,6$ & $-0.816 V_{B C}$ & 60 \\
\hline 11 & $\mathrm{~A}$ & $\mathrm{C}$ & A & $1,8,3$ & $+0.816 V_{A C}$ & 60 \\
\hline 12 & $\mathrm{C}$ & A & $\mathrm{C}$ & $7,2,9$ & $-0.816 V_{A C}$ & 60 \\
\hline 13 & B & B & A & $4,5,3$ & $+0.816 V_{A B}$ & 120 \\
\hline 14 & A & A & $\mathrm{B}$ & $1,2,6$ & $-0.816 V_{A B}$ & 120 \\
\hline 15 & $\mathrm{C}$ & $\mathrm{C}$ & B & $7,8,6$ & $+0.816 V_{B C}$ & 120 \\
\hline 16 & B & $\mathrm{B}$ & $\mathrm{C}$ & $4,5,9$ & $-0.816 V_{B C}$ & 120 \\
\hline 17 & A & A & $\mathrm{C}$ & $7,8,3$ & $+0.816 V_{A C}$ & 120 \\
\hline 18 & $\mathrm{C}$ & $\mathrm{C}$ & A & $1,5,9$ & $-0.816 V_{A C}$ & 120 \\
\hline 19 & A & A & A & $1,2,3$ & 0 & 0 \\
\hline 20 & B & $\mathrm{B}$ & $\mathrm{B}$ & $4,5,6$ & 0 & 0 \\
\hline 21 & $\mathrm{C}$ & $\mathrm{C}$ & $\mathrm{C}$ & $7,8,9$ & 0 & 0 \\
\hline 22 & $\mathrm{~A}$ & $\mathrm{~B}$ & $\mathrm{C}$ & $1,5,9$ & $+V_{i}$ & 0 \\
\hline 23 & A & $\mathrm{C}$ & B & $1,8,6$ & $-V_{i}$ & 0 \\
\hline 24 & $\mathrm{~B}$ & $\mathrm{~A}$ & $\mathrm{C}$ & $4,2,9$ & $-V_{i}$ & 60 \\
\hline 25 & B & $\mathrm{C}$ & A & $4,8,3$ & $+V_{i}$ & 60 \\
\hline 26 & $\mathrm{C}$ & A & $\mathrm{B}$ & $7,2,6$ & $+V_{i}$ & 120 \\
\hline 27 & $\mathrm{C}$ & $\mathrm{B}$ & A & $7,5,3$ & $-V_{i}$ & 120 \\
\hline
\end{tabular}

\subsection{Space Vector Modulation for MC-UPFC}

Based on the sliding surface technique with reference to voltage segment and direct power control for matrix converter gives the switching sequence which allows good steady state performance without errors and good dynamic responses. The behavior of the MC-UPFC can be studied in the real and reactive power aspects.

For the location identification for smooth surface sliding the line voltage is taken for instantaneous location identification. The voltage was segmented in to 12 with the span of 30 degree as shown in Fig. 4. Based on the resultant effect of the injected voltage in $\alpha$-plane are listed 18 possibilities and grouped into 9 positive switching sequences and 9 negative switching sequences.
2.4 Implementation of Sliding Mode Control Technique

Real power $(P)$, reactive power $(Q)$ with degree of one formed with the state variable errors and reference values $P_{e}, Q_{e}$.

$$
\begin{aligned}
& P_{e}=P_{r}-P_{o} \\
& Q_{e}=Q_{r}-Q_{o}
\end{aligned}
$$

The sliding surfaces $P_{f}\left(P_{e}, t\right)$ and $Q_{f}\left(Q_{e}, t\right)$ were estimated with proportional errors.

$$
\begin{gathered}
P_{f}\left(P_{e}, t\right) \stackrel{*}{\Rightarrow} \dot{K_{1}}\left(P_{e}, t\right)=0 \\
Q_{f}\left(Q_{e}, t\right) \stackrel{*}{\Rightarrow} \dot{K_{2}}\left(Q_{e}, t\right)=0
\end{gathered}
$$

The error amplification is obtained with gain constant $K_{1}$ and $K_{2}$ with respect to the switching frequency. The steady state direct power control using the sliding surface technique is a non-linear estimation. 


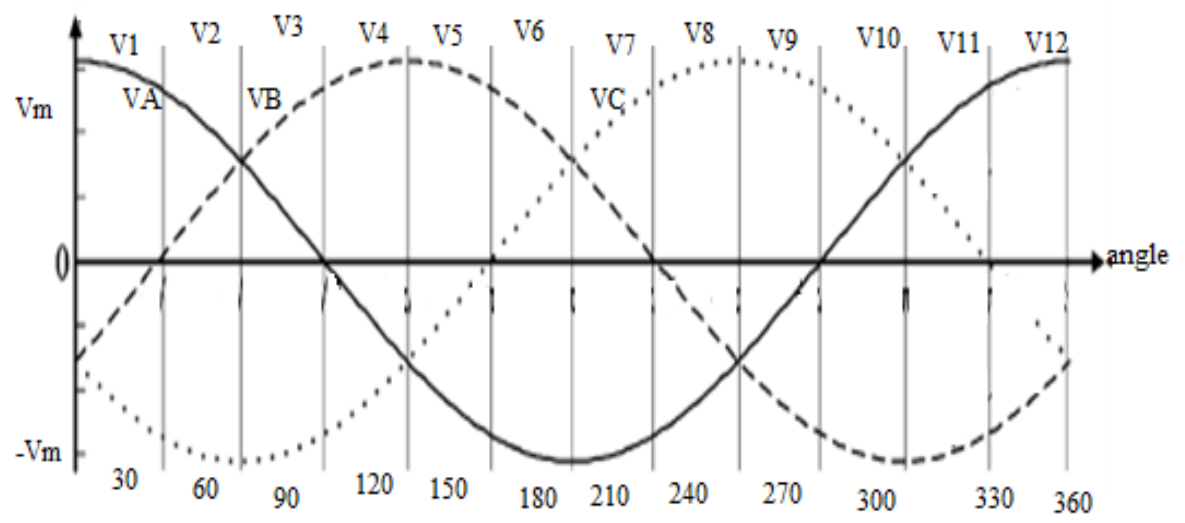

Fig. 4 Sliding mode surface voltage segment.

This switching works with the below stated non-linear law.

$$
\begin{array}{r}
F_{P}\left(P_{e}, t\right) \dot{F}_{P}\left(P_{e}, t\right)<0 \\
F_{Q}\left(Q_{e}, t\right) \dot{F}_{Q}\left(Q_{e}, t\right)<0
\end{array}
$$

This method gives high speed response because of the absence of modulators in system, even pole/zero based controls are also not used. To ensure the correct operation of the circuit to maintain the real and reactive power stability the following sliding surface condition has to be maintained.

(1) If $P_{f}\left(P_{e}, t\right)>0 \stackrel{*}{\Rightarrow} P_{f}\left(P_{e}, t\right)<0 \stackrel{*}{\Rightarrow} P_{o}<P_{r}$ then the sliding mode switching vector should choose the switching scheme to increase the real power.

(2) If $P_{f}\left(P_{e}, t\right)<0 \Rightarrow \dot{F}_{P}\left(P_{e}, t\right)>0 \Rightarrow P_{o}<P_{r}$ then the sliding mode is switching to decrease the real power.

(3) If $P_{f}\left(P_{e}, t\right)=0$, then the switching scheme does not affect the real power.

Similarly to control the reactive power in the bus the switching selector should follow the condition.

(1) If $Q_{f}\left(Q_{e}, t\right)>0, \stackrel{*}{\Rightarrow} \dot{Q_{f}}\left(Q_{e}, t\right)<0 \stackrel{*}{\Rightarrow} Q_{o}<$ $Q_{r}$ then the switching scheme should select the switches to increase the reactive power.

(2) If $Q_{f}\left(Q_{e}, t\right)<0 \Rightarrow \dot{Q}_{P}\left(Q_{e}, t\right)>0 \Rightarrow Q_{o}<$ $Q_{r}$ then the sliding mode switching vector should choose the switching scheme to decrease the reactive power.
(3) If $P_{f}\left(P_{e}, t\right)=0$, then the sliding mode switching vector should choose the switching scheme which does not affect the reactive power.

$$
\begin{gathered}
\dot{F_{P}}\left(P_{e}, t\right)=\int\left(P_{r} d t-P_{o} d t\right) \\
=-\dot{K_{1}} \frac{d P}{d t}=-\dot{K_{1}} \frac{d\left(V_{d} I_{d}\right)}{d t}=-\dot{K_{1}} V_{d} \frac{d\left(I_{d}\right)}{d t}
\end{gathered}
$$

To simplify the understanding of the sliding surface, the alpha beta coordinates $P_{a f}\left(P_{e}, t\right), Q_{f}\left(Q_{b e}, t\right)$ were formed. And for effective control the last six sequence of switching is not used and the sequence from 19 to 21 in Table 2 is treated as zero sequence which was also not used in the control. Therefore in the total 27 state possible switching schemes only 18 effective switching states are used for the real and reactive power control. The control errors from the system are real power error ep, reactive power error eq which are grouped into three levels called hysteresis quantization. From the shunt reactive power which is compared with two-level comparator then nine possible vectors with two levels we obtain 18 possibilities of switching combinations. These 18 combinations are very effective in control strategy.

$$
\dot{F_{Q}}\left(Q_{e}, t\right)=\left(Q_{i r}-Q_{i}\right)+\dot{K_{3}} \frac{d\left(Q_{i r}-Q_{i}\right)}{d t}
$$

Case study 1: if $Q_{f}\left(Q_{e}, t\right)>0, \dot{F}_{Q}\left(Q_{e}, t\right)<0$, then the output vector will vary according to the input matrix converter voltage so we can inject sending voltage to the bus through series transformer to 
Table 2 Switching patterns with current location-2.

\begin{tabular}{|c|c|c|c|c|c|c|c|}
\hline \multirow{3}{*}{$\mathrm{Ca}$} & \multirow{3}{*}{$\mathrm{Cb}$} & \multirow{2}{*}{\multicolumn{2}{|c|}{$\frac{I_{\mathrm{o} 12} \& I_{\mathrm{o} 1}}{\mathrm{Cqi}(\mathrm{v} 1)}$}} & \multirow{2}{*}{\multicolumn{2}{|c|}{$\begin{array}{l}I_{\mathrm{o} 2} \& I_{\mathrm{o} 3} \\
\text { Cqi (v2) }\end{array}$}} & \multirow{2}{*}{\multicolumn{2}{|c|}{$\frac{I_{\mathrm{o} 4} \& I_{\mathrm{o} 5}}{\text { Cqi (v3) }}$}} \\
\hline & & & & & & & \\
\hline & & $\mathrm{P}$ & $\mathrm{M}$ & $\mathrm{P}$ & $\mathrm{M}$ & $\mathrm{P}$ & $\mathrm{M}$ \\
\hline$\overline{\mathrm{L}}$ & $\mathrm{H}$ & 19 & 24 & 21 & 24 & 20 & 21 \\
\hline $\mathrm{L}$ & $\mathrm{Z}$ & 8 & 11 & 8 & 11 & 10 & 7 \\
\hline $\mathrm{L}$ & $\mathrm{L}$ & 13 & 18 & 18 & 15 & 15 & 14 \\
\hline Z & $\mathrm{H}$ & 19 & 24 & 19 & 24 & 20 & 21 \\
\hline Z & $\mathrm{Z}$ & 9 & 10 & 15 & 19 & 17 & 18 \\
\hline Z & $\mathrm{L}$ & 23 & 20 & 23 & 22 & 22 & 19 \\
\hline $\mathrm{H}$ & $\mathrm{H}$ & 17 & 4 & 14 & 17 & 13 & 16 \\
\hline $\mathrm{H}$ & $\mathrm{Z}$ & 12 & 7 & 12 & 9 & 8 & 9 \\
\hline $\mathrm{H}$ & $\mathrm{L}$ & 23 & 20 & 23 & 22 & 22 & 19 \\
\hline
\end{tabular}

achieve it and we must know the location of the power flow at which the power now is available. The 13th and 18th combinations of switches are allowed increasing the voltage among these two possibilities. We need to select one combination of switching sequence.

The UPFC can be controlled with desired switching sequence within the 13 and 18 that will be selected based on the output current location.

If $\dot{F}_{P}\left(P_{e}, t\right)<0,13$ th switching sequence is selected.

If $\dot{F}_{P}\left(P_{e}, t\right)>0,18$ th switching sequence is selected.

If the input reactive power is quantized into two levels $\dot{F}_{P}\left(P_{e}, t\right)<0$ as +1 and $\dot{F}_{q l}\left(q_{e}, t\right)>0$ as -1 , with the same procedure the remaining switching combinations are selected according to its level and location.

The power controller was synthesized using a linear model with the proportional derivative controller. The control voltage with less variation is near point of operation with gain increment,

$$
\frac{\Delta P c}{\Delta P c} \approx \frac{V s}{X 2}
$$

the system's active power dynamics as first order system.

\section{PID Controller for MC-UPFC}

The time constant for the PI controller can be given as $T i$, by choosing PI controller which assures the zero steady state error.

Proportional gain constant is $K_{p} V_{\mathrm{s}}$; integral gain constant is $K_{i}$.

Maintaining the stability of the controller system, the pole zero cancellation is done and the tuned transfer function of the closed loop system is stated as To measure. The resultant control values of real and reactive power del $p c$ and $d e l q c$ were obtained and fed to the matrix convert switches to drive the high frequency venturini based PWM circuit.

$$
\begin{aligned}
& m_{k, j}(t)=\frac{1}{3}+1 / 3\left\{\frac{v_{k} v_{j}}{v^{2}}+\right. \\
& \left.\left(\frac{4}{3 \sqrt{3}}\right) q \sin \left(\omega t-\beta_{k}\right) \sin (3 \omega t)\right\}
\end{aligned}
$$

$J=$ output parameters A, B, C. $Q=v_{k} v_{k}$.

$\beta_{k}=0,2 \mathrm{t} / 3,4 \mathrm{t} / 3$ where $k=$ input parameters a, $\mathrm{b}, \mathrm{c}$.

This method of PWM is designed to control the sinusoidal voltage magnitude and angle of the real power and reactive power near to the unity power factor. The system proposed is the control block of the linear controller. It can control the real power $(P)$ and reactive power $(Q)$ simultaneously without depending on other.

$$
C_{p}(s)=K p\left[\frac{1+s T_{\mathrm{ip}}}{s T_{\mathrm{ip}}}\right]
$$

The block diagram shown in Fig. 5 is the closed loop control schematic with that DPC (direct power control) 
Table 3 Switching patterns based on voltage location-1.

\begin{tabular}{|c|c|c|c|c|c|c|c|}
\hline & \multirow{3}{*}{$\mathrm{Cb}$} & \multicolumn{2}{|c|}{$I_{06} \& I_{07}$} & \multicolumn{2}{|c|}{$I_{08} \& I_{09}$} & \multicolumn{2}{|c|}{$I_{\mathrm{o} 10} \& I_{\mathrm{o} 11}$} \\
\hline & & \multicolumn{2}{|c|}{ Cqi (v4) } & \multicolumn{2}{|c|}{ Cqi (v5) } & \multicolumn{2}{|c|}{ Cqi (v6) } \\
\hline & & $\mathrm{P}$ & $\mathrm{M}$ & $\mathrm{P}$ & $\mathrm{M}$ & $\mathrm{P}$ & $\mathrm{M}$ \\
\hline $\mathrm{L}$ & $\mathrm{H}$ & 20 & 23 & 23 & 22 & 22 & 19 \\
\hline $\mathrm{L}$ & $\mathrm{Z}$ & 7 & 12 & 12 & 9 & 8 & 9 \\
\hline $\mathrm{L}$ & $\mathrm{L}$ & 14 & 17 & 16 & 17 & 13 & 16 \\
\hline Z & $\mathrm{H}$ & 20 & 23 & 23 & 22 & 8 & 19 \\
\hline Z & Z & 10 & 9 & 19 & 20 & 17 & 18 \\
\hline $\mathrm{Z}$ & $\mathrm{L}$ & 24 & 19 & 21 & 24 & 20 & 21 \\
\hline $\mathrm{H}$ & $\mathrm{H}$ & 18 & 13 & 18 & 15 & 15 & 14 \\
\hline $\mathrm{H}$ & $\mathrm{Z}$ & 11 & 8 & 10 & 11 & 10 & 7 \\
\hline $\mathrm{H}$ & $\mathrm{L}$ & 24 & 19 & 21 & 24 & 20 & 24 \\
\hline
\end{tabular}

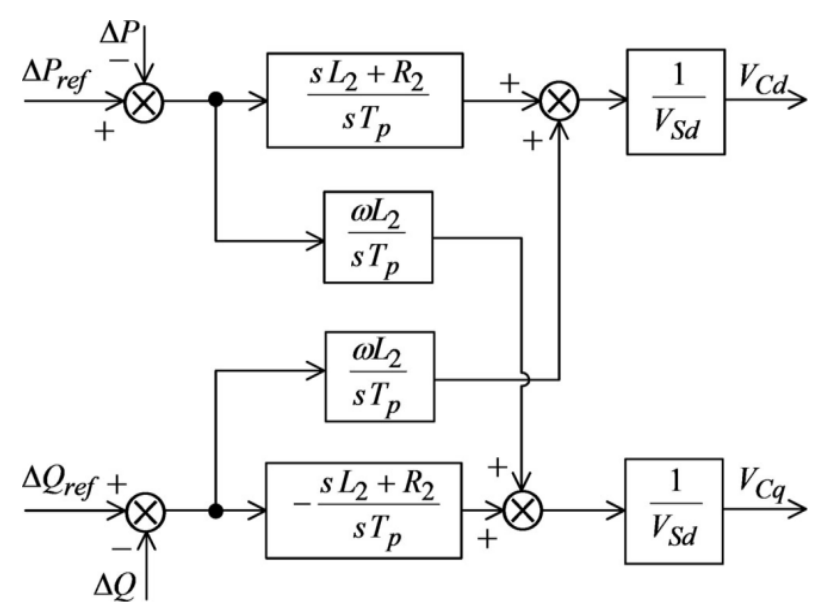

Fig. 5 Block diagram of decoupled controller.

has double PI regulators to generate control signals $v_{c d}$ and $v_{c q}$ which are given to the PWM block of the Matrix converter. The surface of the linearized sliding mode is calculated with reference to the source voltage in direct axis which is given as $v_{s d}$. The power errors can be defined as difference between the $p$ and $p_{\text {ref }}$. which can be given as follows.

$$
\begin{array}{r}
{\left[\begin{array}{l}
\Delta P \\
\Delta Q
\end{array}\right]=\frac{1}{s T_{p}}\left[\begin{array}{l}
\Delta P_{\text {ref }}-\Delta P \\
\Delta Q_{\text {ref }}-\Delta Q
\end{array}\right]} \\
{\left[\begin{array}{l}
V_{d c} \\
V_{q c}
\end{array}\right]=\frac{1}{s T_{p}} \frac{1 G c}{V s d}\left[\begin{array}{l}
\Delta P_{r e f}-\Delta P \\
\Delta Q_{\text {ref }}-\Delta Q
\end{array}\right]}
\end{array}
$$

The closed loop control system with the above voltage signal is fed to the PI controller, which has the following response.

$$
\left[\begin{array}{l}
V_{d c} \\
V_{q c}
\end{array}\right]=\frac{1}{V s d}\left[\begin{array}{l}
\frac{S L 2+R 2}{s T_{p}}-\frac{\omega L 2}{s T_{p}} \\
\frac{\omega L 2}{s T_{p}}-\frac{s L 2+R 2}{s T_{p}}
\end{array}\right]\left[\begin{array}{l}
\Delta P_{r e f}-\Delta P \\
\Delta Q_{r e f}-\Delta Q
\end{array}\right]
$$

\subsection{Simulation of $M C-U P F C$}

The PI based controller implemented MC-UPFC is simulated and tested in two cases based on the proportional and integral constant of the real and reactive power and the time response. The schematic arrangement of the power system simulation is shown in Fig. 6. Two generators were connected to the power system one in the sending end named as sending end generator. The second generator is connected in the receiving end and both the generators will feed the load through the transmission line.

The space vector function is further converted into the direct and quadrature axis component and to reduce the complexity the control data flow was converted into alpha, beta coordinates. Based on the error and reference values the control signal for the real power control and reactive power control was converted into the switching signal.

With the help of the MATLAB simulator in the Simulink platform the power system with two-bus was designed and the pi-network transmission line was included in Figs. 7 and 8. To simulate the modeled system power GUI is assigned with discrete conduction and sampling mode. The block diagram connection arrangement was shown in Fig. 6.

In MC-UPFC each switch is arranged in $3 \times 3$ matrix converter, each switch is a bi-directional switch setup as shown in Fig. 7. To construct a matrix converter this switch setup is arranged in a matrix sequence as shown 


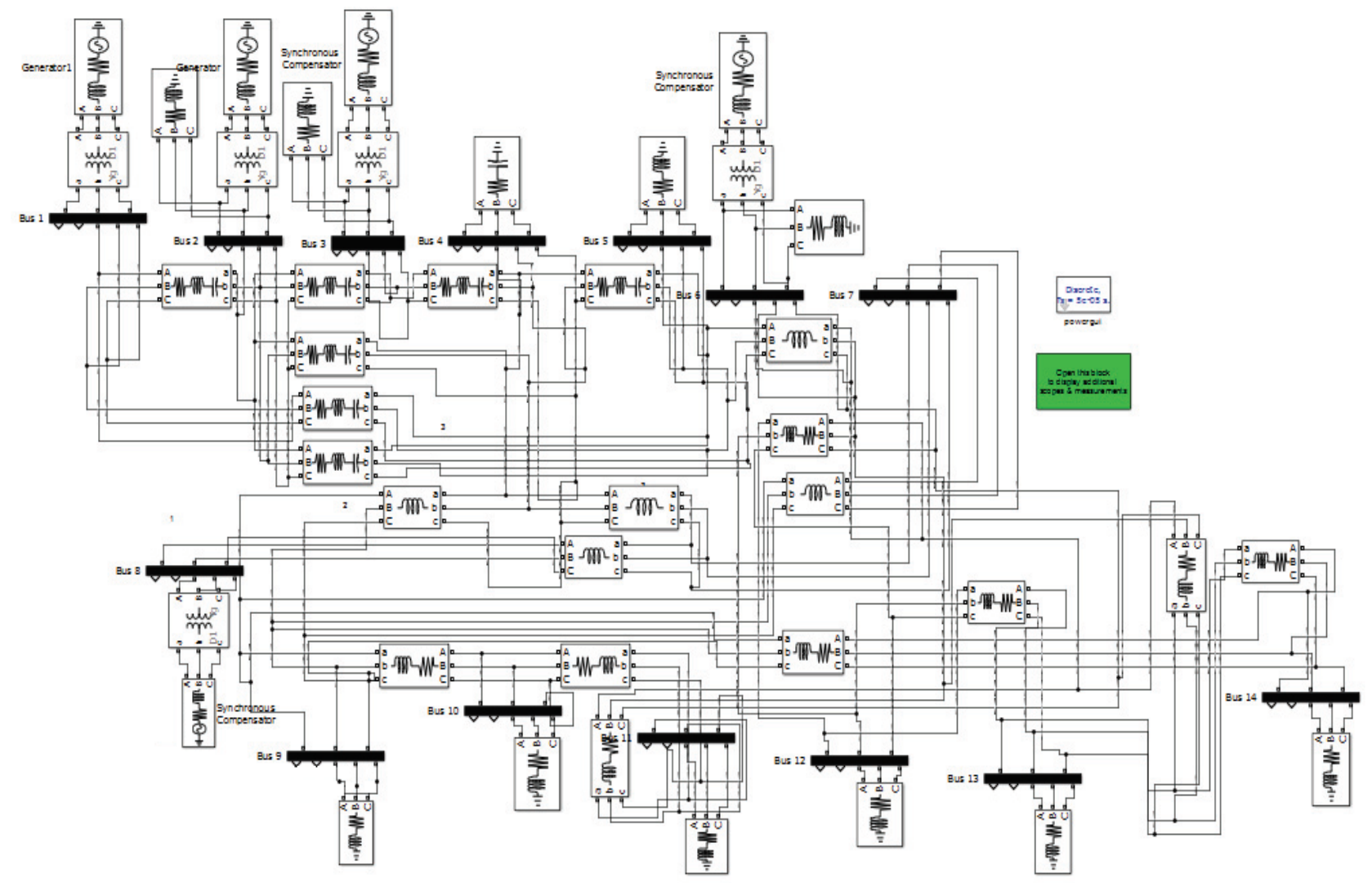

Fig. 6 MATLAB simulink arrangement of IEEE-14 bus power system.

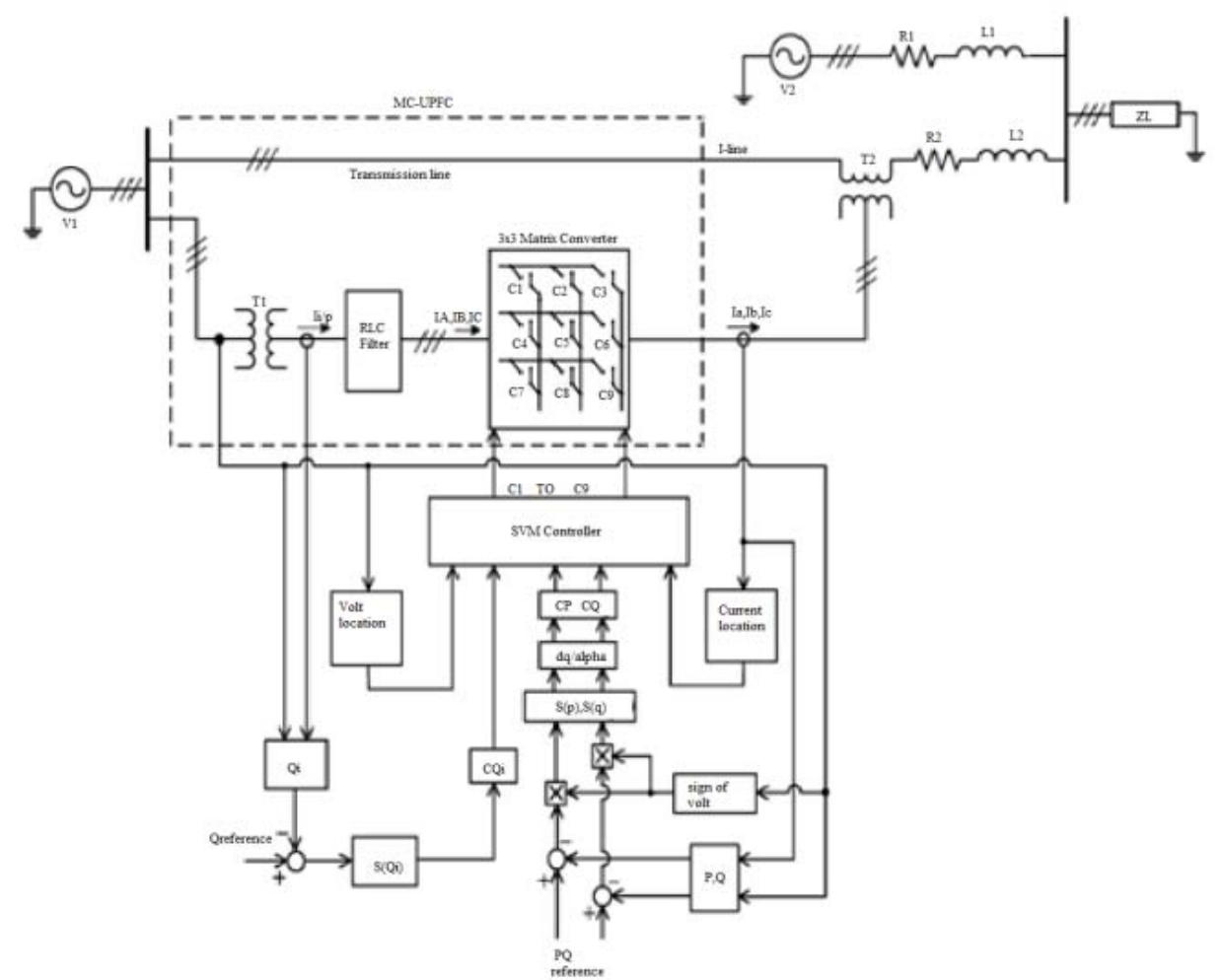

Fig. 7 Block diagram of sliding mode SVM MC-UPFC. 


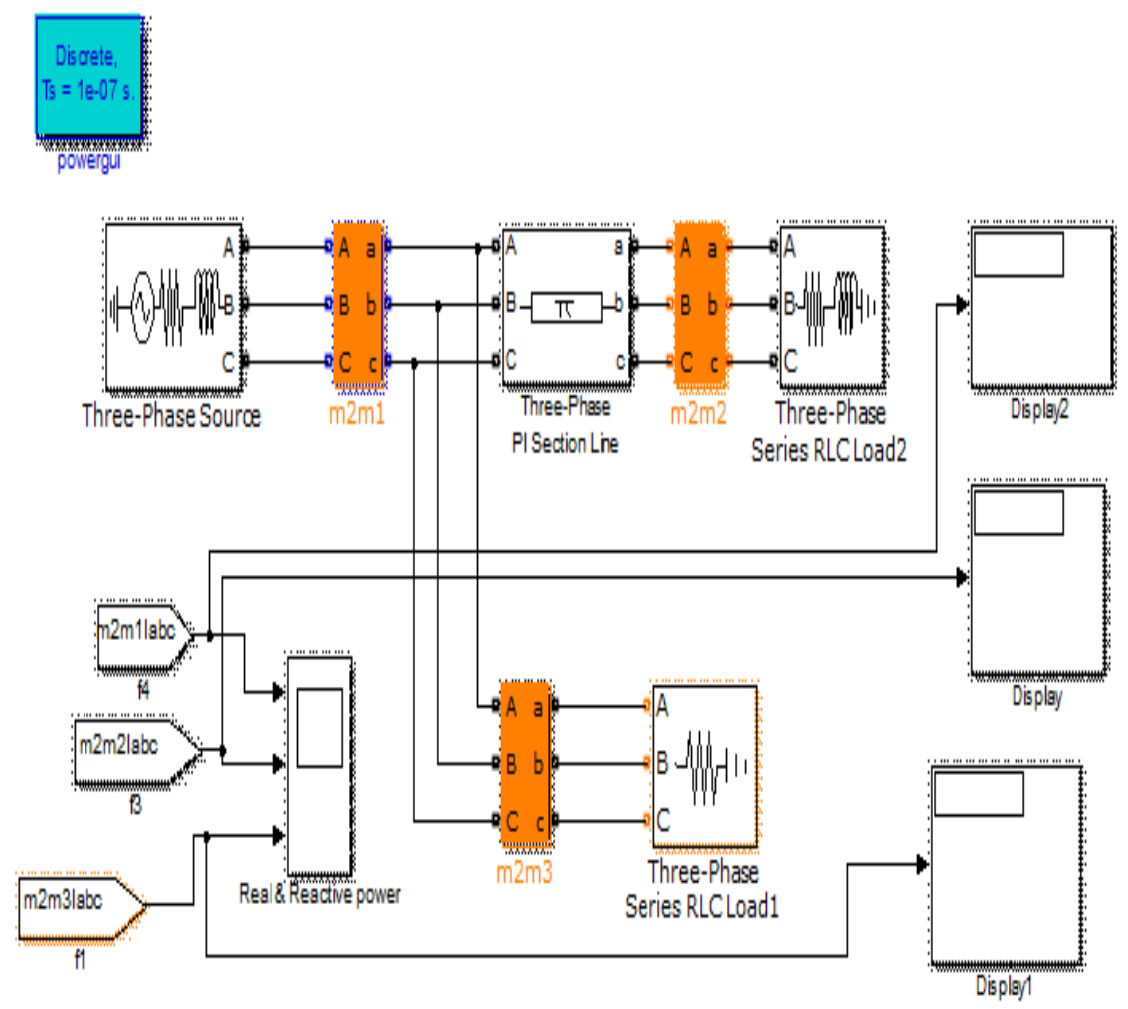

Fig. 8 Simulation of 2-bus power system using MATLAB.

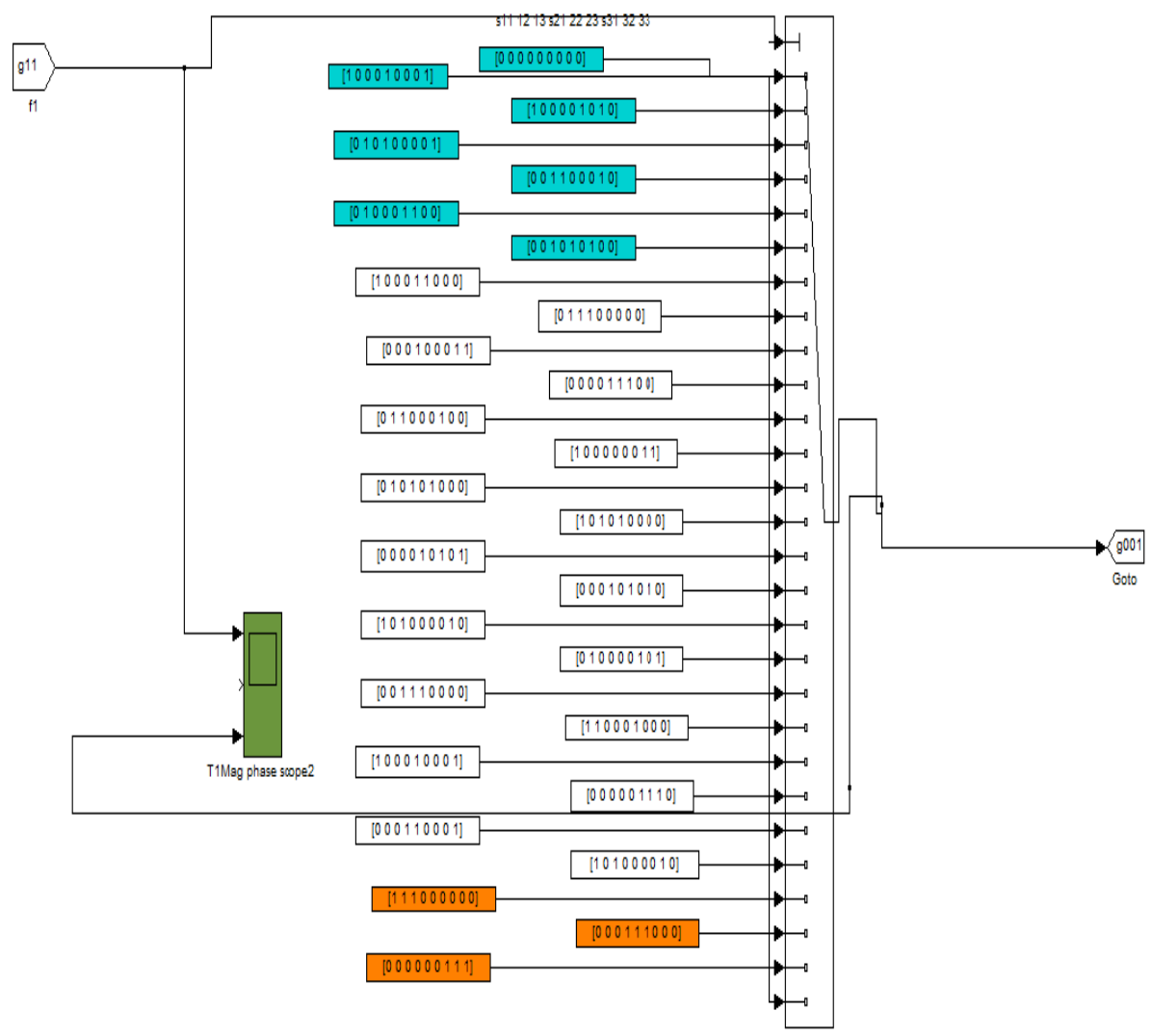

Fig. 9 Switching table \& selector switch for MC-UPFC. 


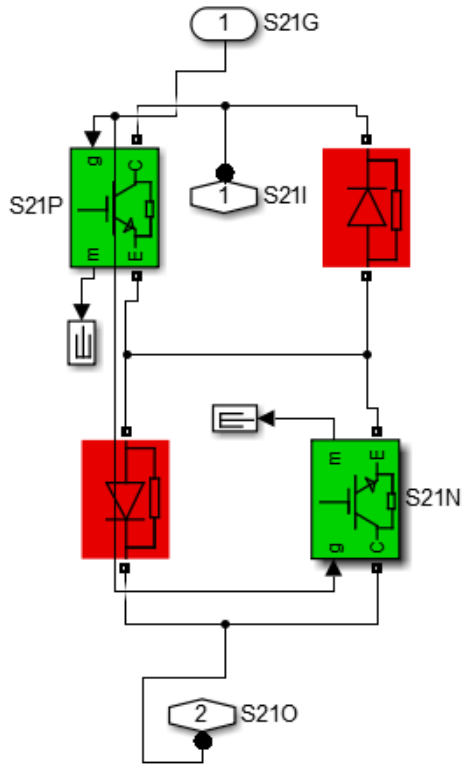

Fig. 10 Simulation of bi-directional switch for MC-UPFC.

in Fig. 8. To facilitate three input phases it will be injected to any of the output phase independently. Above block representation of a MATLAB simulink helps to understand the switching arrangements where R-phase can be injected to any of the output phase, similarly Y-phase and B-phase represented in red, yellow and blue blocks.

Fig. 9 shows the sequential arrangement of switching pulse values of the matrix converter switches among which any one of the sequences will be connected to the gates.

In Fig. 10, the bi-directional switching arrangement made in the simulator using back to back coupled IGBT with free-wheeling diode connection is shown.

\section{Fuzzy Logic Controller}

The design and control of fuzzy logic to enhance the performance of the MC-UPFC to improve the power flow in the power system is in this section. A multi layer FLC technique is developed to control the system. The computational algorithm development and performance test is given below. The FLC design is made based on the knowledge on power system information, MC-UPFC control parameters, system output.
The basic components of FLC are listed below:

(1) fuzzification;

(2) inference;

(3) knowledge base;

(4) rule base;

(5) defuzzification;

(6) controlled input;

(7) controlled output;

(8) centroid.

The centroid is working based on the identification of the center of any area, also called as center of gravity. The centroid can be obtained as shown in Fig. 11.

\subsection{Implementation of PID Based FLC}

The FLC with self tuning is an adaptive controller with incremental FLC parameters based on the PI controller rules. For the adaptive control the FLC uses value of error and the rate at which occurs is considered in time-varying system, where $k_{p}$ is proportional controller gain, $k_{d}$ is derivative.

$$
u(k)=k_{p} e(k)+k_{i} \sum k_{d}[e(k)-e(k-1)]
$$

The flow chart shown in Fig. 12 explains the control data flow with the reference input and the controlled signal given to switching circuit. The real and reactive power available in the bus is taken as measured value and it was compared with the reference real and reactive power. Based on the PID control using FLC inference the switching scheme is given as output with reference to the fuzzy rule base which was listed in Table 4.

Fig. 13 shows the design diagram of fuzzy inference system block where fuzzy input and output system is declared. The FLC was designed with the mamdani system with centroid functions as shown in Fig. 14.

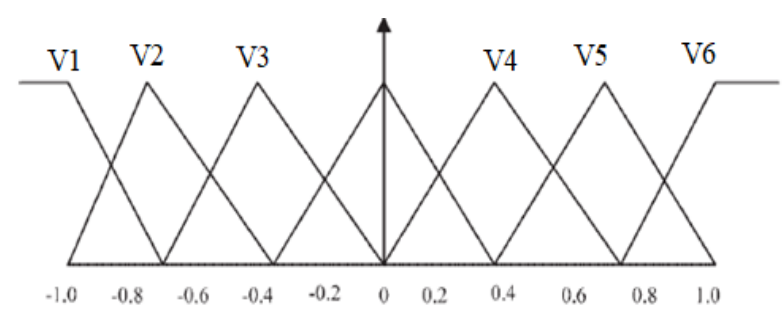

Fig. 11 Centroid representation of fuzzy logic controller. 
Table 4 Fuzzy rule base.

\begin{tabular}{lllllllllllll}
\hline & V1 & V2 & V3 & V4 & V5 & V6 & V7 & V8 & V9 & V10 & V11 & V12 \\
\hline I1 & S1 & S2 & S4 & S6 & S8 & S10 & S12 & S14 & S16 & S18 & S1 & S3 \\
I2 & S3 & S1 & S2 & S6 & S8 & S10 & S10 & S14 & S16 & S18 & S1 & S3 \\
I3 & S5 & S2 & S1 & S2 & S6 & S8 & S10 & S10 & S14 & S16 & S18 & S3 \\
I4 & S7 & S7 & S2 & S1 & S2 & S6 & S8 & S10 & S14 & S16 & S18 & S1 \\
I6 & S9 & S9 & S7 & S2 & S1 & S2 & S6 & S8 & S10 & S14 & S16 & S18 \\
I7 & S11 & S11 & S9 & S7 & S2 & S1 & S2 & S6 & S8 & S10 & S14 & S16 \\
I8 & S13 & S13 & S11 & S9 & S7 & S2 & S1 & S2 & S6 & S8 & S10 & S14 \\
I9 & S15 & S15 & S13 & S11 & S9 & S7 & S2 & S1 & S2 & S6 & S8 & S10 \\
I10 & S17 & S17 & S15 & S13 & S11 & S9 & S7 & S2 & S1 & S2 & S6 & S8 \\
I11 & S2 & S2 & S17 & S15 & S13 & S11 & S9 & S7 & S2 & S1 & S2 & S2 \\
I12 & S4 & S4 & S2 & S17 & S15 & S13 & S11 & S9 & S7 & S2 & S1 & S1 \\
\hline
\end{tabular}

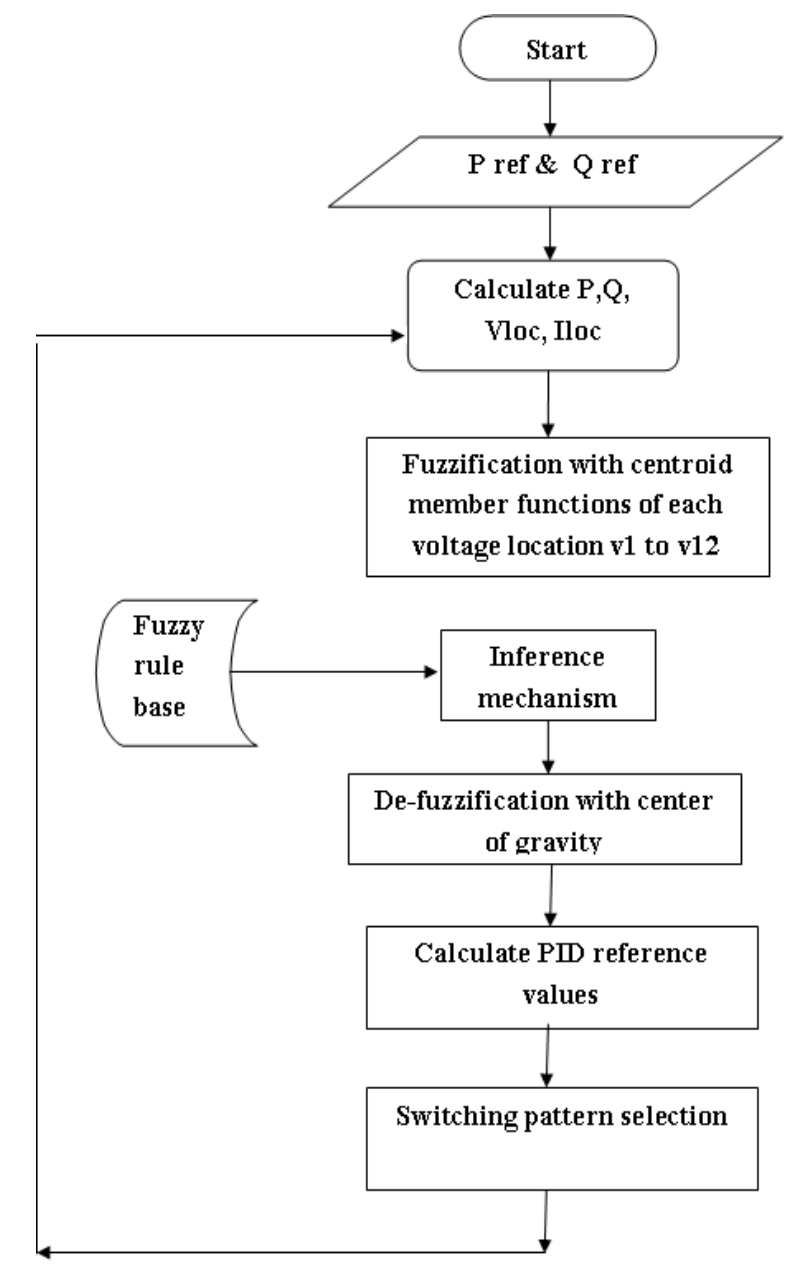

Fig. 12 Flow chart of fuzzy logic controller.

\section{ANN Based Control for MC-UPFC}

In this section the AI based power flow is controlled using the ANN (Artificial Neural Network). The technique proposed is investigated with different bus and cases. To achieve the objective power system is modeled and control parameter based on the ANN and FLC is obtained with effective algorithms and solved the power system operation to control the real and reactive power flow and compared with the previous controlling methods. The MC-UPFC is connected to the power system and controlled switching signal was given by the ANN system. The injected voltage and angle are controlled by selecting the relevant switches.

This work comprises of the power system modeling in the ANN based control aspect. A new algorithm was developed to improve the power flow through the control of transmission parameters in terms of real and reactive power control. This was achieved by the voltage injection.

\subsection{Calculating ANN Control Parameters}

The ANN is implemented to calculate the error voltage which is the difference between the actual available value in the bus and the reference value given as the pre set value. After calculating the gap between the required and available power parameters with the help of an ANN algorithm selection of switches to be switched (ON/OFF), duration of the switching and optimal way controlling the power are achieved.

To understand the function of the neural network with three to four layer feed forward system has input layer as first layer and hidden layer as second layer and third layer as output layer. In this system the input layer gets the error voltage of the real and reactive 
power and the output layer gives the equivalent value of voltage to be injected and the angle at which the voltage is to be injected. This structure is called feed forward structure.

Fig. 15 shows the structure of the ANN network with the inputs layer $\times 1, \times 2, \ldots, \times m$ number of inputs, $o 1$, $o 2, \ldots, o k$ number of outputs and $n 1, n 2, \ldots, n n$ number of hidden layers with different weight levels respectively.

\subsection{Learning through Back Propogation}

(1) Randomly initializing the weights of the input, output and hidden layer.

(2) Learning the tuning of the network with input and corresponding target layer.

(3) Finding the error weight value fed by the ANN to the other device as output.

$$
\begin{array}{ll}
B P_{e r}^{1}=O_{1}^{N N(T)} & O_{1}^{N N(o)} \\
B P_{e r}^{2}=O_{2}^{N N(T)} & O_{2}^{N N(o)}
\end{array}
$$

$$
B P_{e r}^{k}=O_{k}^{N N(T)} O_{k}^{N N(o)}
$$

where $O_{k}^{N N(T)}$ is $k^{\text {th }}$ network target, $O_{k}^{N N(o)}$ is current node output.

(4) Determine each layer instantaneous output.

$$
\begin{aligned}
& O_{1}^{N N(o)}=D_{1} \prod_{N=1}^{n} w_{1} O_{1}^{N N}(n) \\
& O_{2}^{N N(o)}=D_{2} \prod_{N=1}^{n} w_{2} O_{2}^{N N}(n) \\
& O_{k}^{N N(o)}=D_{k} \prod_{N=1}^{n} w_{k} O_{k}^{N N}(n)
\end{aligned}
$$

where $D_{1}, D_{2}$ and $D_{k}$ are bias functions.

$$
\begin{aligned}
& O_{1}^{N N}(n)=1 / 1 \exp \left(w_{1 n} o_{1} w_{2 n} o_{2}\right) \\
& O_{2}^{N N}(n)=1 / 1 \exp \left(w_{1 n} o_{1} w_{2 k} o_{2}\right) \\
& O_{k}^{N N}(n)=1 / 1 \exp \left(w_{k n} o_{1} w_{k n} o_{2}\right)
\end{aligned}
$$

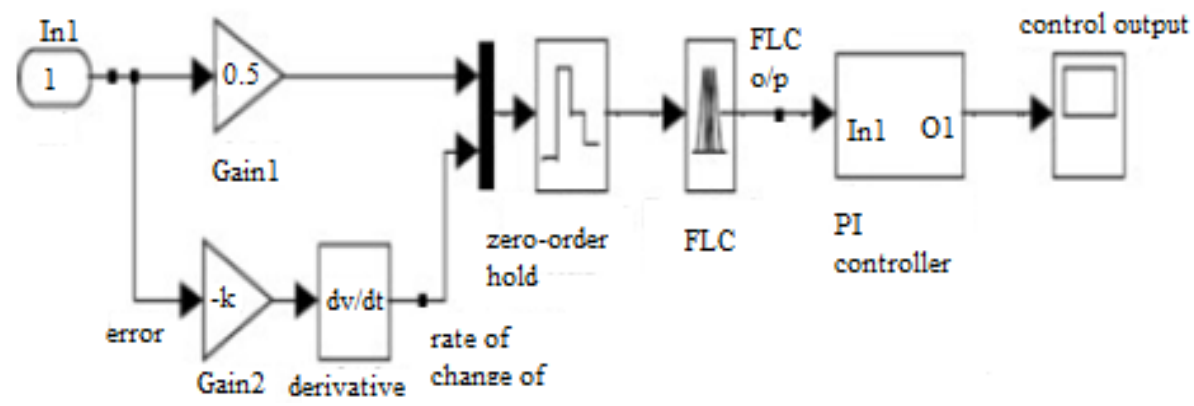

Fig. 13 Functional block diagram of FLC.
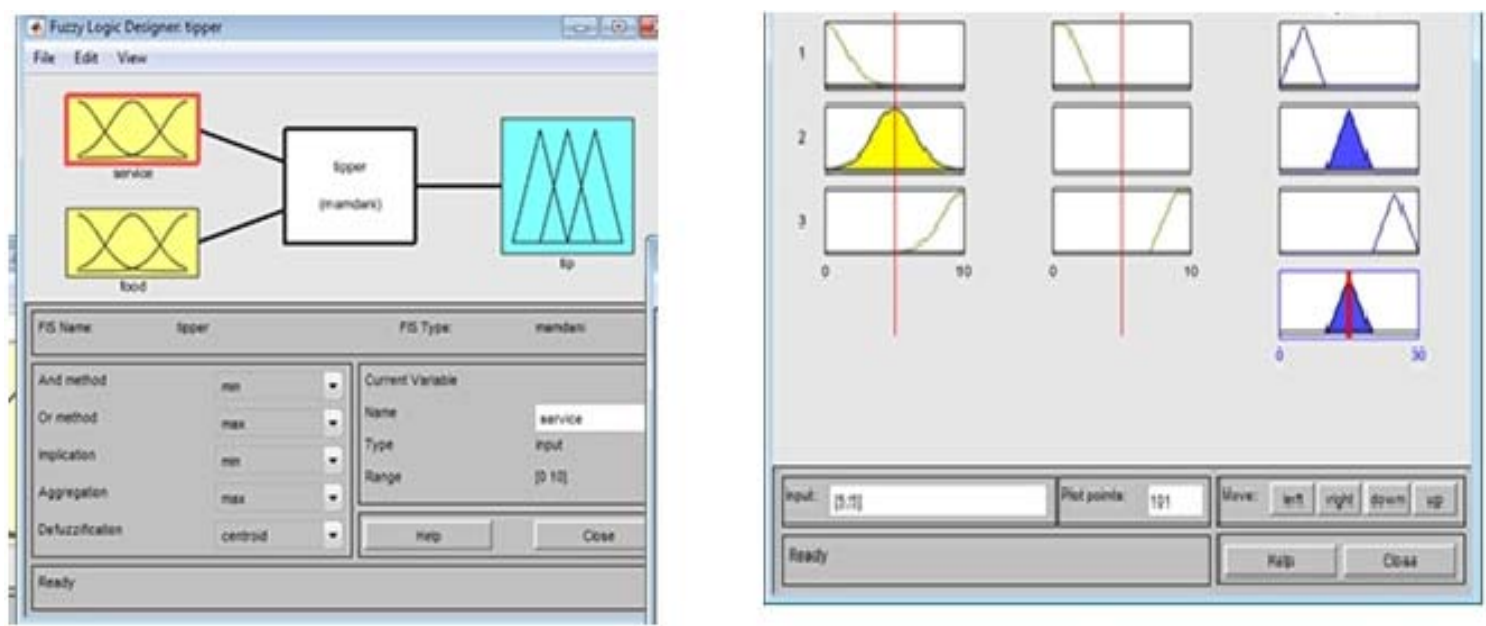

Fig. 14 Input and output member function of FLC. 


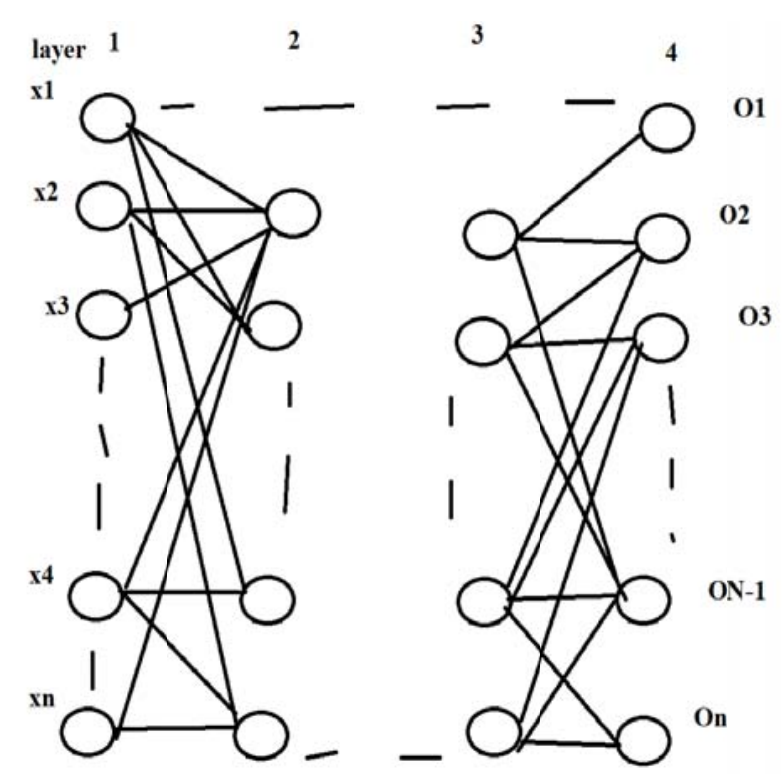

Fig. 15 ANN feed forward layer.

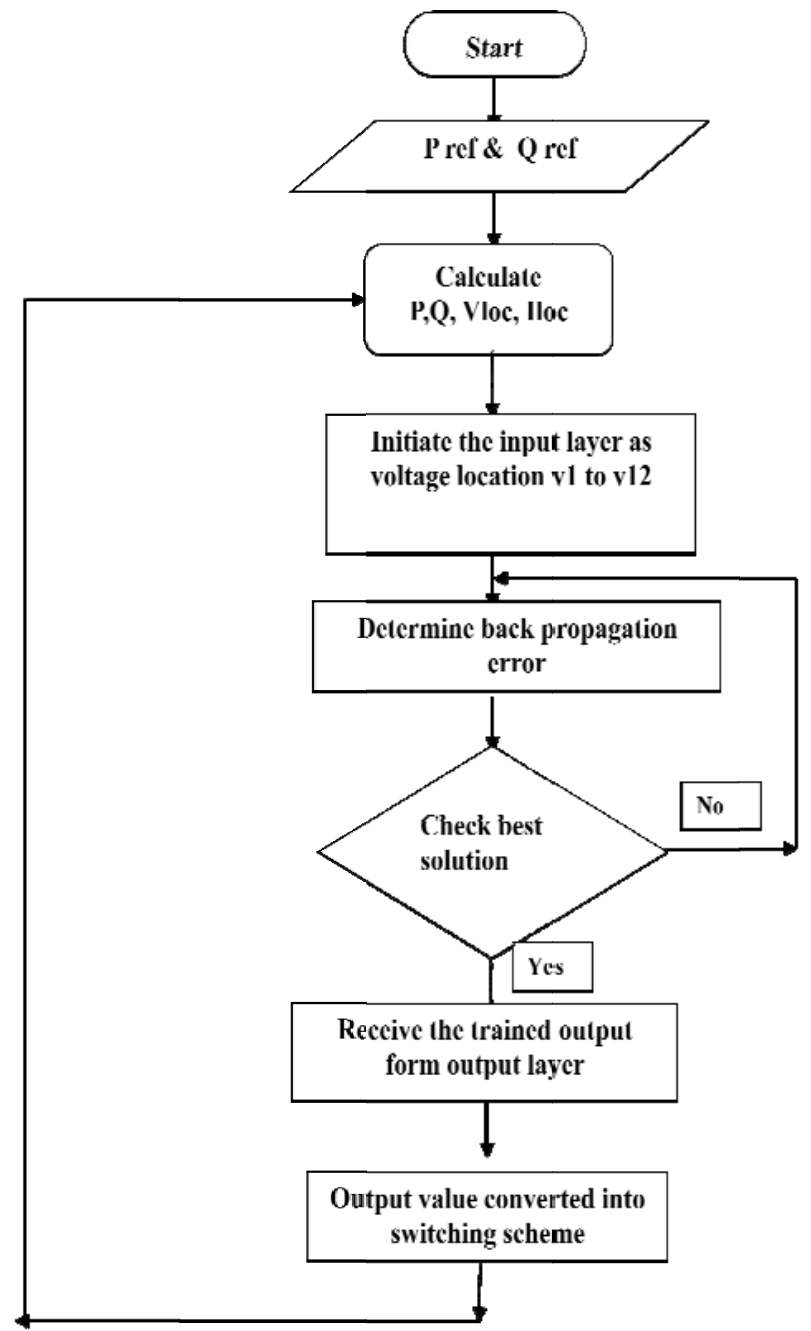

Fig. 16 Flow chart of ANN feed forward network.
(5) Updated weights of every neuron of the neural network achieved by the learning of neurons, the weight change is obtained as:

$$
\begin{aligned}
& \nabla w_{1}=G \cdot o_{1} \cdot B P_{e r}^{1} \\
& \nabla w_{2}=G \cdot o_{2} \cdot B P_{e r}^{2} \\
& \nabla w_{k}=G \cdot o_{k} \cdot B P_{e r}^{k}
\end{aligned}
$$

where, $G$ is learning rate, 0.2 to 0.5 .

(6) Train the system by repeating the above steps to minimize the error.

After completing the training process of the ANN, identification of the voltage is to be injected and also the angle is done using the following flowchart steps.

Fig. 16 shows the control flow estimation of the ANN controller to give the control sequence signal for switching scheme. The power reference and the input power available in the bus are sampled and tuned with weighted index. The indexed value is sampled by segmentation and connected with the reference look-up switching table.

\subsection{Simulation and Results}

The power system controlled by MC-UPFC using ANN is designed with MATLAB simulink using Artificial Neural Network control sub block. The simulation of different bus power system was shown in Fig. 17 and the sub blocks which convert the sampled and reference data are compared and segmented for logation identification.

The controller decision made based on the power reference, error value of control parameter $(P$ or $Q)$ with location based on the input voltage, the output current and output voltage. The output of this system is given to the selector switch of the switching schema control based on the switching sequence.

\subsection{Case Study Using Simulation of ANN}

The ANN based controller for MC-UPFC is developed and tested with different power system conditions. The reference power is fixed as same as the other controllers dealt in Sections 3 and 4. The bus real 
power flow is set as 0.7 p.u., the performance of the system with different bus powers systems is dealt in this following section and the performance is analyzed.

\subsubsection{Test Case 1-2-Bus System with ANN}

As mentioned in Section 2 the bus consists of a power source with $80 \mathrm{MVA}$ as real power and $20 \mathrm{MVA}$ as reactive power. The MC-UPFC is injecting the active power to maintain the reference real power value.
ANN produces the control signal to operate the controller.

The generator is loaded through the transmission system $P 1=0.7$ as real power and $Q 1=0.2$ as reactive power. For the given reference value the power maintained up to 0.64 and the time taken to settle is $t=$ $0.056 \mathrm{sec}$ shown in Figs. 18-20. The THD (total harmonic distortion) is reduced as $8 \%$.

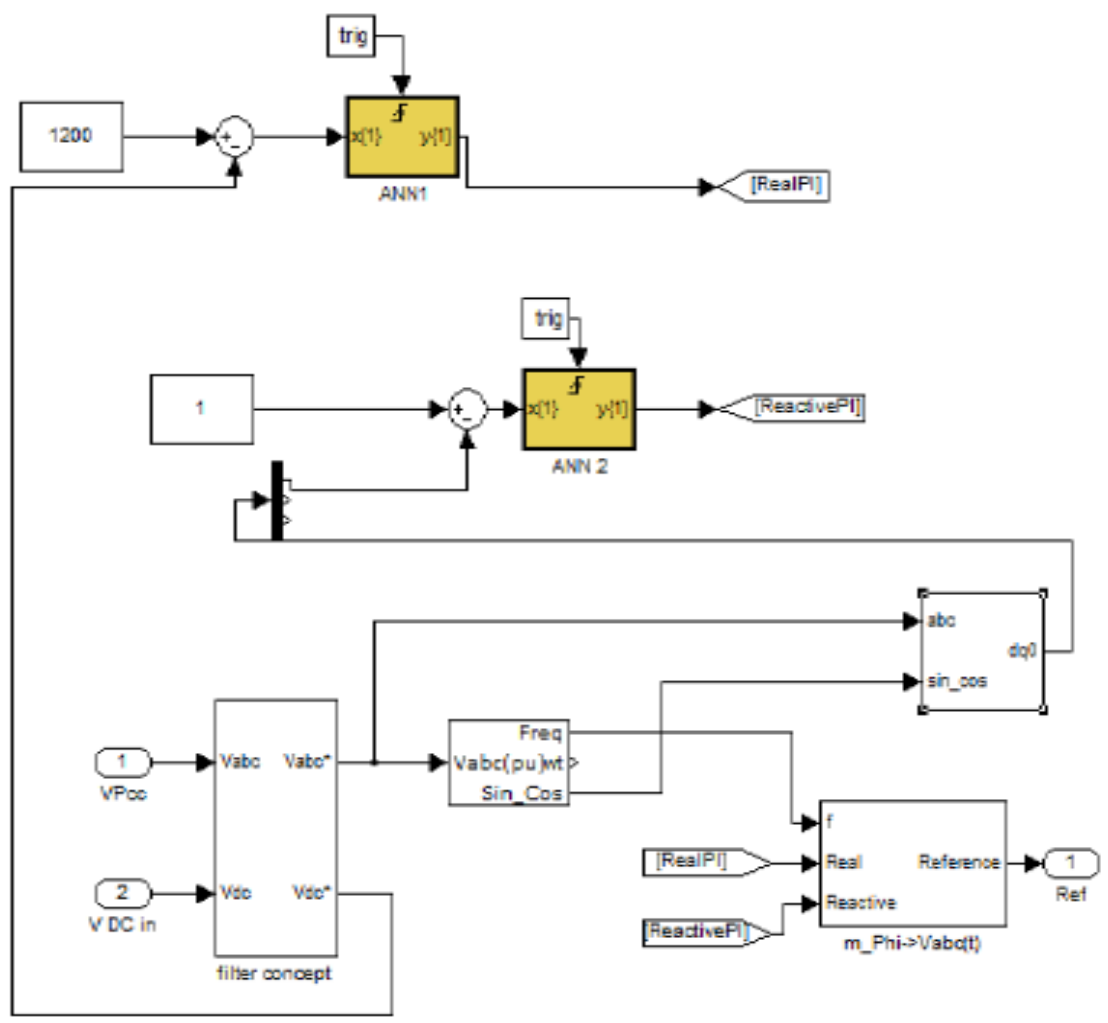

Fig. 17 P-control schematic using ANN in 14-bus.

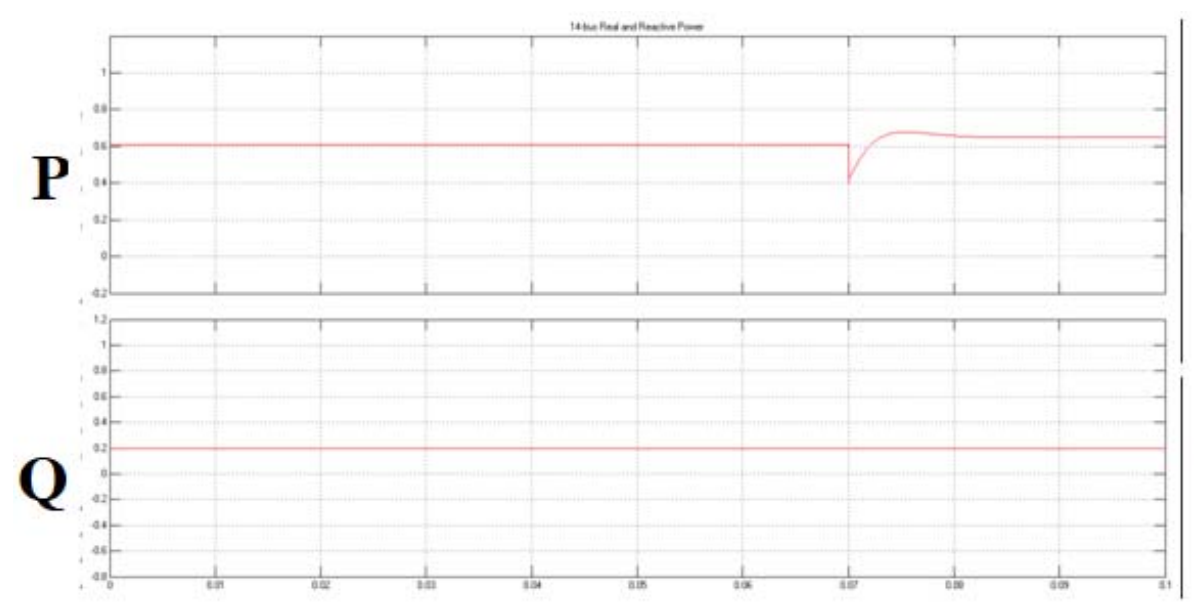

Fig. 18 P-control response using ANN in 14-bus. 

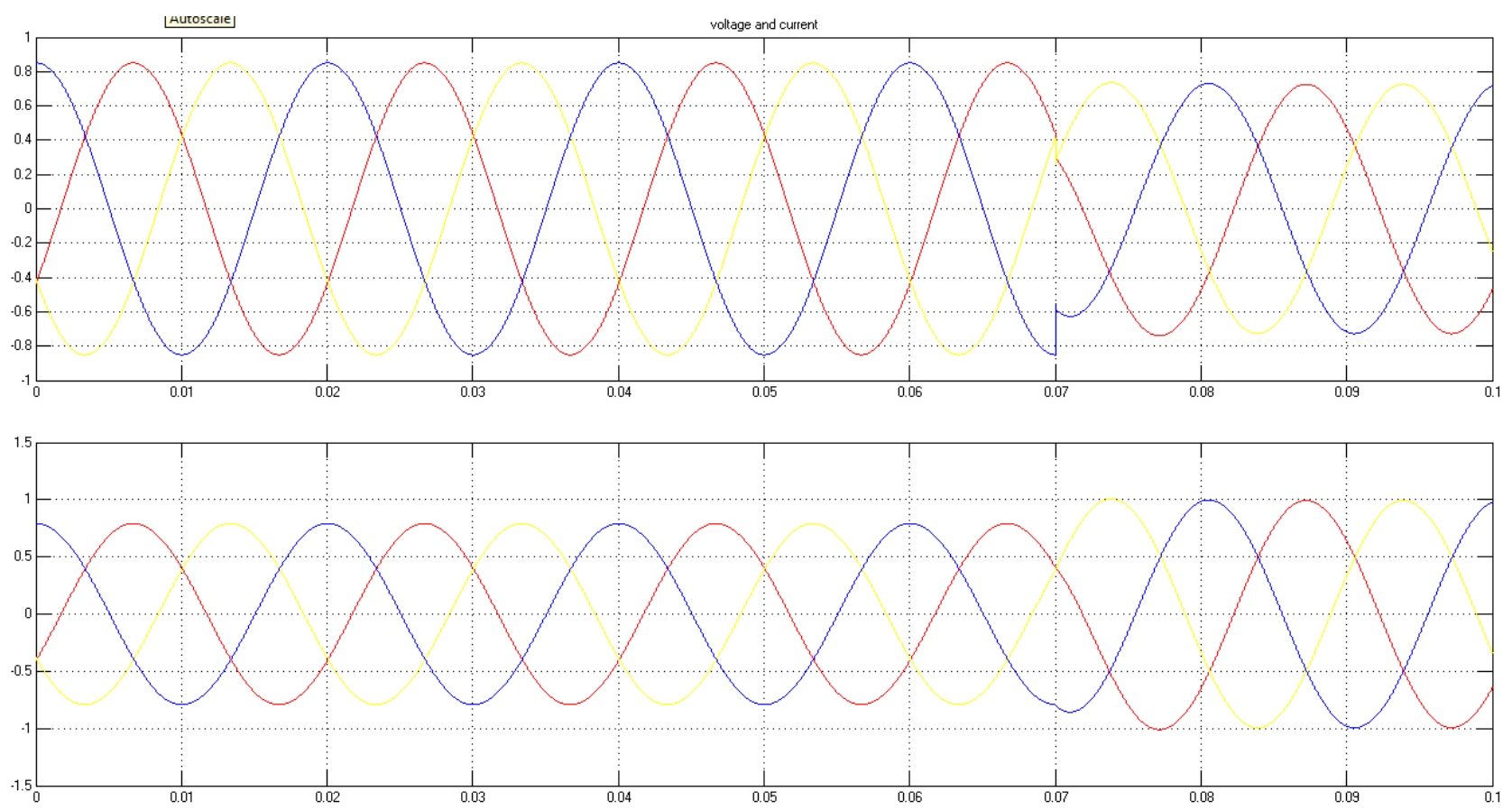

Fig. 19 Bus voltage and MC-UPFC control voltage in ANN 14-bus system.

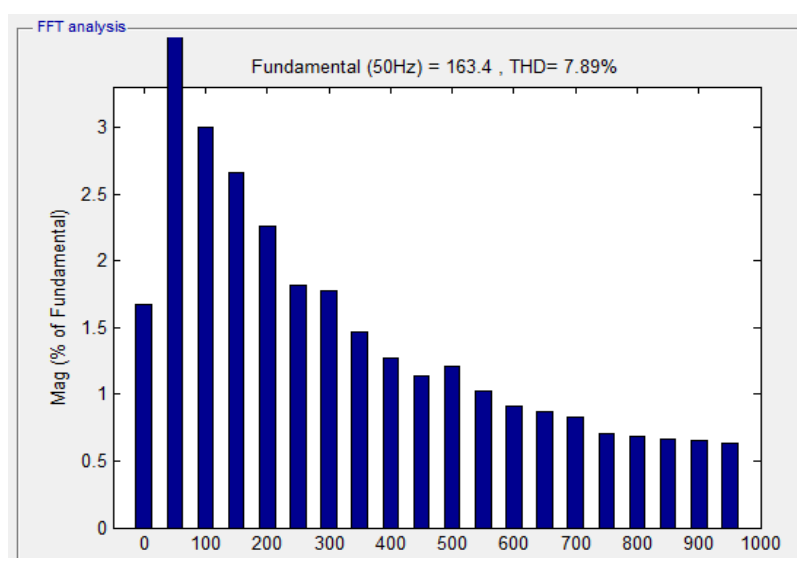

Fig. 20 THD of MC-UPFC under ANN for 14-bus system.

\subsubsection{Test Case 2-9-Bus System with ANN}

In the 9-bus system ANN controller is installed across the bus $4 \& 5$. The reference value is set as 0.7 p.u. at the controlled bus. The 3 generators are feeding the power system. The real power on the control region is improved up to 0.0645 p.u.

The time taken to response after switcing the controller is $t=0.007 \mathrm{sec}$. The THD value is reduced as $7.96 \%$.

5.4.3 Test Case 3-IEEE 14-Bus System with ANN Controller

The IEEE 14-bus is taken for simulation and checking the loading capability of ANN based controller for MC-UPFC. The power flow is maintained as 0.66 p.u. The power flow variation after switching the ANN based MC-UPFC is shown in Figs. 18 and 19. The time response of the ANN controller for 14-bus system is $t=0.007 \mathrm{sec}$. The THD for the switching scheme is $7.89 \%$ shown in Fig. 20.

\subsection{Performance Analysis}

As a means of increasing the power transfer ability of the bus in the power system, this thesis provides the design of the MC-UPFC and the performance was analyzed with different switching strategies such as PID/SVM, FLC, ANN controllers.

From the above charts performance based on the real power obtained in the load bus highlighted in Fig. 21, time response by settling time highlighted in Fig. 22 and total harmonic distortion shown in Fig. 23 for different buses 2,9 and 14 .

\section{Conclusion}

From the experiments conducted in the simulation platform using MATLAB/SIMULINK, it is concluded 


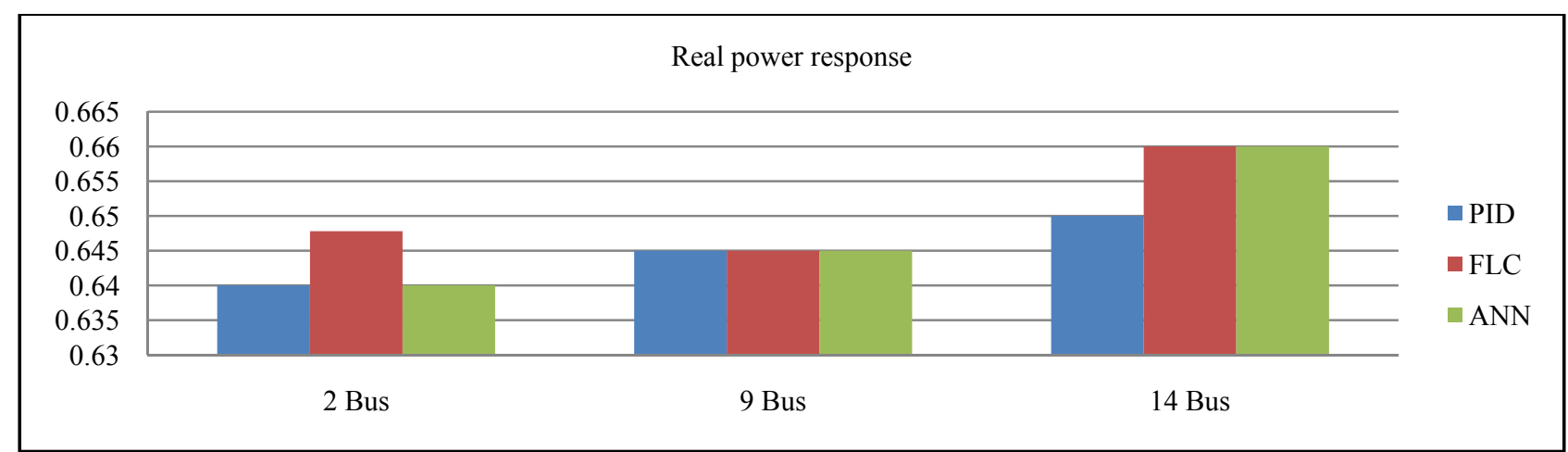

Fig. 21 Comparison based on real power control.

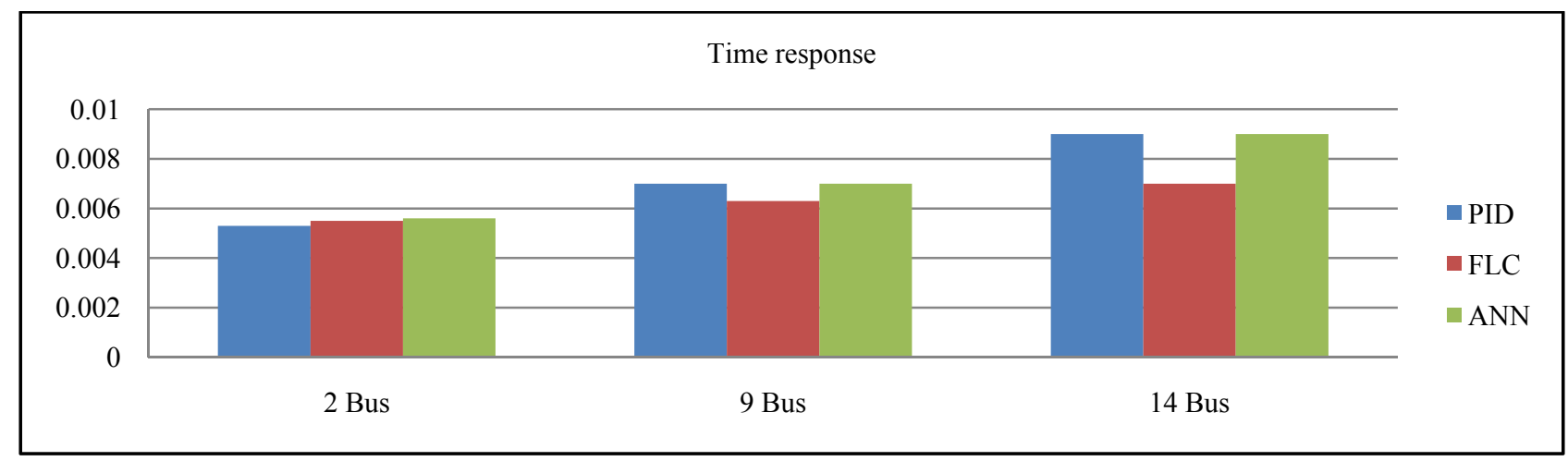

Fig. 22 Comparison based on time response (settling time).

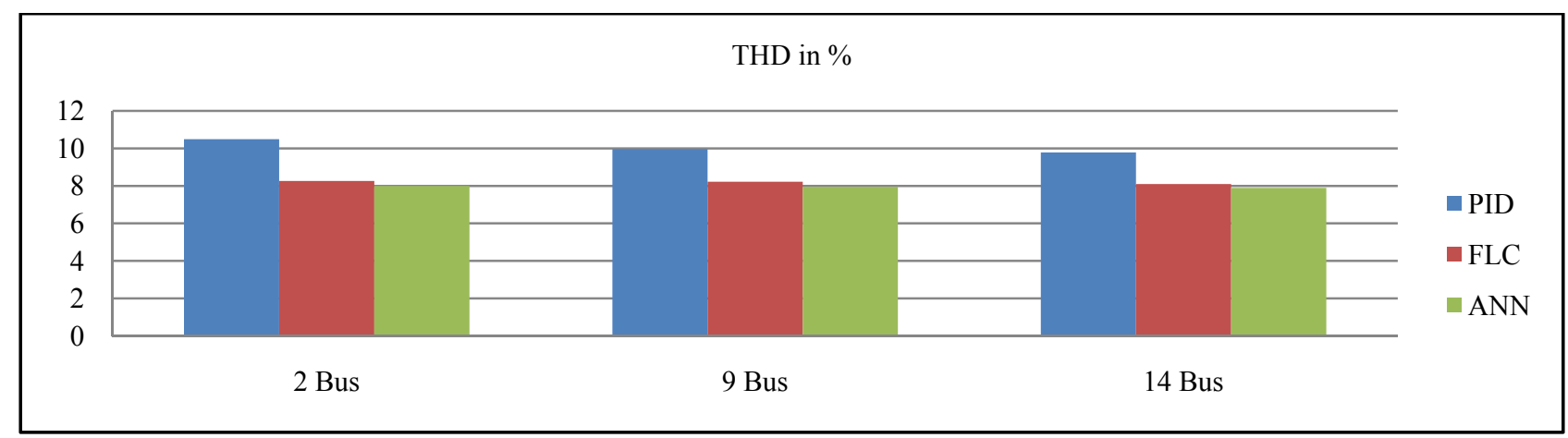

Fig. 23 Comparison based on total harmonic distortion.

that the MC-UPFC with artificial intelligence based on switching algorithm acts as optimum control for the power flow in the power system. The designed control algorithms for MC-UPFC in this research work presented in the thesis are reducing loss and increasing the power utilization. The AI based FLC and ANN algorithms for MC-UPFC are identified as suitable for the faster voltage control technique. Modeling of the MC-UPFC based power system with voltage injection control parameter gives good response in control strategies input error identification. In general the application of the more MC-UPFC in power system gives good power flow and improved efficiency by reducing loss.

\section{Future Work}

As a continuation to this work, other methods of artificial intelligence can be developed and performance can be analyzed. MC-UPFC can be implemented for the micro grid power systems. MC 
based device can be modified and implemented in the hybrid power systems. IPFC (inter line power flow controller) can be implemented with the ANN and FLC algorithms.

\section{References}

[1] Gyuigi, L., Schauder, C. D., Williams, S. L., Rietman, T. R., Torgerson, D. R., and Edris, A. 1995. "The Unified Power Flow Controllers: A New Approach to Power Transmission Control." IEEE Trans. on Power Delivery 10 (2): 1085-97.

[2] Papic, I., Zunko, P., and Povh, D. 1997. "Basic Control of Unified Power Flow Controller." IEEE Trans. on Power Systems 12 (4).

[3] Padiyar, K. R., and Kulkarni, A. M. 1998. "Control Design and Simulation of Unified Power Flow Controller." IEEE Trans. on Power Delivery 13 (4).

[4] Fujota, H., Watanabe, Y., and Akagi, H. 1999. "Control and Analysis of Unified Power Flow Controller." IEEE Trans. on Power Electronics 14 (6).

[5] Wang, H. F. 1999. "Application of Modelling UPFC into Mkulti-Machine Power System.” IEE Prac.-Gener. Transm Distrib. 146 (3).

[6] Arabi, S., Kundur, P., and Adapa, R. 2000. "Innovative Techniques in Modeling UPFC for Power System Analysis.” IEEE Trans. on Power System 15 (1).

[7] Liu, L., Zhu, P., Kang, Y., and Chen, J. 2007. "Power-Flow Control Performance Analysis of a Unified Power Flow Controller in Novel Control Scheme." IEEE Trans. on Power Delivery 22 (3).

[8] Shotorbani, A. M., Ajami, A., Zadeh, S. G., Aghababa, M. P., and Mahboubi, B. 2014. "IET Gener." Transm. Distrib. 8 (10): 1712-23.

[9] Yuan, J., Liu, L., Fei, W., et al. 2016. "Hybrid Electromagnetic Unified Power Flow Controller: A Novel Flexible and Effective Approach to Control Power Flow." IEEE Trans. on Power Delivery.

[10] Biswas, S., and Nayak, P. K. 2018. "State-of-the-Art on the Protection of FACTS Compensated High-Voltage Transmission Lines: A Review." IET Trans. on High Volt. 3 (1).

[11] Ooi, B.-T., and Kazerani, M. 1998. "Voltage-Source Matrix Converter as a Controller in Flexible AC Transmission Systems." IEEE Trans. on Power Delivery 13 (1).

[12] Wheeler, P., Clare, J., Empringham, L., Apap, M., and Bland, M. 2002. "Matrix Converters." Power Engineering Journal.

[13] Gupta, R. K., Mohapatra, K. K., Somani, A., and Mohan, N. 2010. "Direct-Matrix-Converter-Based Drive for a Three-Phase Open-End-Winding AC Machine with
Advanced Features." IEEE Trans. on Industrial Electronics 57 (12).

[14] Iqbal, A., Moin Ahmed, S. K., Abu-Rub, H. 2012. "Space Vector PWM Technique for Tree-to-Five-Phase Matrix Converter." IEEE Trans. on Industry Application 48 (2).

[15] Diaz, M., Cardenas, R., Rojas, F., and Clare, J. 2014. "3-Phase 4-Wire Matrix Converter-Based Voltage Sag/Swell Generator to Test Low-Voltage Ride through in Wind Energy Conversion Systems." IET Power Electronics 7 (12): 3116-25.

[16] Ali, M., Iqbal, A., Khan, M. R., Ayyub, M., and Anees, M. A. 2016. "Generalized Theory and Analysis of Scalar Modulation Techniques for a $\mathrm{M} \times \mathrm{N}$ Matrix Converter." Trans. On Power Electronics 32 (6): 4864-77.

[17] Sun, Y., Ziong, W., Su, M., Li, X., Dan, H., and Yang, J. 2016. "Carrier-Based Modulation Strategies for Multimodular Matrix Converters." IEEE Trans. on Industrial Electronics 63 (3).

[18] Dasgupta, A., Tripathy, P., and Sensarma, P. S. 2007. "Matrix Converter as UPFC for Transmission Line Compensation." Presented at 7th International Conference on Power Electronics 2007, Daegu, Korea.

[19] Monterio, J., Fernando Silva, J., Pinto, S. F., and Palma, J. 2011. "Matrix Converter-Based Unified Power Flow Controllers: Advanced Direct Power Control Method." IEEE Trans. on Power Delivery 26 (1).

[20] Monterio, J., Fernando Silva, J., Pinto, S. F., and Palma, J. 2014. "Linear and Sliding-Mode Control Design for Matrix Converter-Based Unified Power Flow Controllers." IEEE Trans. on Power Electronics 29 (7).

[21] Villarroel, F., Espinoza, J. R., Rojas, C. A., Rodriguez, J., Rivera, M., and Sabrbaro, D. 2013. "Multi Objective Switching State Selector for Finite-States Model Predictive Control Based on Fuzzy Decision Making in a Matrix Converter." IEEE Trans. on Industrial Electronics 60 (2).

[22] Sri Vidya, D., and Venkatesa, T. 2017. "Quasi-Z-Source Indirect Matrix Converter Fed Induction Motor Drive for Flow Control of Dye in Paper Mill." IEEE Trans. on Power Electronics.

[23] Menniti, D., Pinnarelli, A., and Sorrentino, N. 2000. "A Novel Fuzzy Logic Controller for UPFC.” In Proceedings PowerCon 2000.

[24] Farrag, M. E. A., Putrus, G. A., and Ran, L. 2002. "Design of Fuzzy Based-Rules Control System for the Unified Power Flow Controller.” Presented at IEEE 28th Annual Conference of the Industrial Electronics Society.

[25] Tang, A., Yuan, Y., and Cheng, S. 2008. "The Study of Fuzzy-Logic Self-Adaptive Controller for UPFC." Presented at 2008 Control and Decision Conference.

[26] Prasad, C. E., and Vadhera, S. 2015. "Damping of Sub Synchronous Resonance Using Fuzzy Based PI Controlled 
UPFC."

[27] Kumar, R., and Kumar, M. 2015. "Improvement Power System Stability Using Unified Power Flow Controller Based on Hybrid Fuzzy Logic-PID Tuning in SMIB System.” Presented at 2015 International Conference on Green Computing and Internet of Things.

[28] Mohant, A., Patra, S., and Ray, P. K. "Robust Fuzzy-Sliding Mode UPFC Controller for Transient
Stability Analysis in Autonomous Wind-Diesel-PV Hybrid System." IET Generation Transmission \& Distribution 10 (5): 1248-57.

[29] Albatsh, F. M., Mekhelef, S., Ahmad, S., and Mokhils, H. 2017. "Fuzzy Logic Based UPFC and Laboratory Prototype Validation for Dynamic Power Flow Control in Transmission Lines." IEEE Trans. on Industrial Electronics.

\section{Appendix A}

Table A1 Line resistance and reactance between buses.

\begin{tabular}{llllll}
\hline \multirow{2}{*}{ Bus number } & \multirow{2}{*}{ Voltage } & \multicolumn{3}{c}{ Load impedance } & \multicolumn{2}{c}{ Line impedance } \\
\cline { 3 - 6 } & & Resistance & Inductance & Resistance & Inductance \\
\hline Bus 2 & $11 \mathrm{kV}$ & $5 \Omega$ & $15 \mathrm{mH}$ & $5 \Omega$ & $15 \mathrm{mH}$ \\
Bus 1 & $11 \mathrm{kV}$ & $65 \Omega$ & $50 \mathrm{mH}$ & $5 \Omega$ & $15 \mathrm{mH}$ \\
\hline
\end{tabular}

Table A2 Line resistance and reactance between buses.

\begin{tabular}{llllll}
\hline \multirow{2}{*}{ Bus number } & \multirow{2}{*}{ Voltage } & \multicolumn{3}{c}{ Load impedance } & \multicolumn{2}{c}{ Line impedance } \\
\cline { 3 - 6 } & & Resistance & Inductance & Resistance & Inductance \\
\hline Bus 1 & $11 \mathrm{kV}$ & $5 \Omega$ & $15 \mathrm{mH}$ & $5 \Omega$ & $15 \mathrm{mH}$ \\
Bus 2 & $11 \mathrm{kV}$ & $65 \Omega$ & $150 \mathrm{mH}$ & $5 \Omega$ & $15 \mathrm{mH}$ \\
Bus 3 & $11 \mathrm{kV}$ & - & - & $5 \Omega$ & $15 \mathrm{mH}$ \\
Bus 4 & $11 \mathrm{kV}$ & - & - & $5 \Omega$ & $15 \mathrm{mH}$ \\
Bus 5 & - & $50 \Omega$ & $150 \mathrm{mH}$ & $5 \Omega$ & $15 \mathrm{mH}$ \\
Bus 6 & - & $100 \Omega$ & $300 \mathrm{mH}$ & $5 \Omega$ & $15 \mathrm{mH}$ \\
Bus 7 & - & - & - & $5 \Omega$ & $15 \mathrm{mH}$ \\
Bus 8 & $11 \mathrm{kV}$ & - & - & $5 \Omega$ & $15 \mathrm{mH}$ \\
Bus 9 & $11 \mathrm{kV}$ & $65 \Omega$ & $500 \mathrm{mH}$ & $5 \Omega$ & $15 \mathrm{mH}$ \\
\hline
\end{tabular}

Table A3 Line resistance and reactance between buses.

\begin{tabular}{llllll}
\hline \multirow{2}{*}{ Bus number } & \multirow{2}{*}{ Voltage } & \multicolumn{2}{c}{ Load impedance } & Line impedance \\
\cline { 3 - 5 } & & Resistance & Inductance & Resistance & Inductance \\
\hline Bus 1 & $11 \mathrm{kV}$ & $5 \Omega$ & $15 \mathrm{mH}$ & $5 \Omega$ & $15 \mathrm{mH}$ \\
Bus 2 & $11 \mathrm{kV}$ & $65 \Omega$ & $150 \mathrm{mH}$ & $5 \Omega$ & $15 \mathrm{mH}$ \\
Bus 3 & $11 \mathrm{kV}$ & - & - & $5 \Omega$ & $15 \mathrm{mH}$ \\
Bus 4 & $11 \mathrm{kV}$ & - & - & $5 \Omega$ & $15 \mathrm{mH}$ \\
Bus 5 & - & $50 \Omega$ & $150 \mathrm{mH}$ & $5 \Omega$ & $15 \mathrm{mH}$ \\
Bus 6 & - & $100 \Omega$ & $300 \mathrm{mH}$ & $5 \Omega$ & $15 \mathrm{mH}$ \\
Bus 7 & - & - & - & $5 \Omega$ & $15 \mathrm{mH}$ \\
Bus 8 & $11 \mathrm{kV}$ & - & - & $5 \Omega$ & $15 \mathrm{mH}$ \\
Bus 9 & $11 \mathrm{kV}$ & $65 \Omega$ & $500 \mathrm{mH}$ & $5 \Omega$ & $15 \mathrm{mH}$ \\
Bus 10 & $11 \mathrm{kV}$ & $5 \Omega$ & $15 \mathrm{mH}$ & $5 \Omega$ & $15 \mathrm{mH}$ \\
Bus 11 & $11 \mathrm{kV}$ & $65 \Omega$ & $150 \mathrm{mH}$ & $5 \Omega$ & $15 \mathrm{mH}$ \\
Bus 12 & $11 \mathrm{kV}$ & - & - & $5 \Omega$ & $15 \mathrm{mH}$ \\
Bus 13 & $11 \mathrm{kV}$ & - & - & $5 \Omega$ & $15 \mathrm{mH}$ \\
Bus 14 & - & $50 \Omega$ & $150 \mathrm{mH}$ & $5 \Omega$ & $15 \mathrm{mH}$ \\
\hline
\end{tabular}

